\title{
A PHASE DIAGRAM FOR TURBULENT, TRANSITIONAL AND LAMINAR CLAY SUSPENSION FLOWS
}

\author{
JACO H. BAAS ${ }^{1}$, JAMES L. BEST ${ }^{2}$, JEFFREY PEAKALL ${ }^{3}$ AND MI WANG $^{4}$ \\ ${ }^{1}$ School of Ocean Sciences, Bangor University, Menai Bridge, Anglesey, LL59 5AB, United \\ Kingdom.E-mail: j.baas@bangor.ac.uk \\ ${ }^{2}$ Departments of Geology and Geography and Ven Te Chow Hydrosystems Laboratory, University \\ of Illinois at Urbana-Champaign, 1301 W. Green St., Urbana, Illinois 61801, USA. E-mail: \\ jimbest@uiuc.edu \\ ${ }^{3}$ Earth and Biosphere Institute, Institute of Geological Sciences, School of Earth and Environment, \\ University of Leeds, Leeds LS2 9JT, United Kingdom. E-mail: j.peakall@earth.leeds.ac.uk \\ ${ }^{4}$ School of Process, Environmental and Materials Engineering, University of Leeds, Leeds LS2 \\ 9JT, United Kingdom.E-mail: m.wang@leeds.ac.uk
}

Keywords: Flume experiments; Clay flows; Turbulence modulation; Transitional Flows; Flow Phase Diagram; Kaolin 


\begin{abstract}
New phase diagrams for the dynamic structure of clay-laden open-channel flows are proposed. These diagrams can be used to distinguish between turbulent Newtonian, transitional, and laminar non-Newtonian flow behavior, on the basis of the balance between turbulent forces (approximated by the horizontal components of flow velocity and turbulence intensity) and cohesive forces (approximated by the suspended clay concentration and rheology). Stability regimes for five different flow types are defined using a comprehensive series of laboratory flume experiments at depth-averaged flow velocities ranging from $0.13 \mathrm{~m}$ $\mathrm{s}^{-1}$ to $1.47 \mathrm{~m} \mathrm{~s}^{-1}$, and at volumetric kaolinite clay concentrations ranging from $0.03 \%\left(=0.8 \mathrm{~g} \mathrm{~L}^{-1}\right)$ to $16.7 \%(=$ $434 \mathrm{~g} \mathrm{~L}^{-1}$ ). As clay concentration increases, five flow types can be distinguished: turbulent flow, turbulenceenhanced transitional flow, lower and upper transitional plug flow, and quasi-laminar plug flow.

The turbulent properties of transitional flows are shown to be considerably more complex than the common notion of gradual turbulence damping. Turbulence-enhanced transitional flows display higher turbulence intensity than turbulent flows of similar velocity, with such enhancement originating from development of a highly turbulent basal internal shear layer within $\sim 0.01 \mathrm{~m}$ of the bed. In lower transitional plug flows, the basal internal shear layer separates a lower region of high vertical gradient in horizontal velocity and strong turbulence from an upper region of plug flow with a much gentler velocity gradient and lower turbulence intensity. Kelvin-Helmholtz shear instabilities within the highly turbulent shear layer are expressed as distinct second-scale oscillations in the time series of downstream velocity. Turbulence damping dominates upper transitional plug flows, because strong cohesive forces, inferred to be caused by gelling of the highconcentration clay suspension, start to outbalance turbulent forces. In quasi-laminar plug flows, gelling is pervasive and turbulence is fully suppressed, apart from some minor residual turbulence near the base of these flows.

With very few exceptions, all flows pass through the same development stages as clay concentration increases, regardless of their velocity, but the threshold concentrations for turbulence enhancement, gelling, and development of internal shear layers and plug flows are proportional to flow velocity. At flow velocities below $\sim 0.5 \mathrm{~m} \mathrm{~s}^{-1}$, only low concentrations $(<0.75 \%)$ of kaolinite are required to induce transitional flow behavior, thus potentially affecting many slow-moving and decelerating clay flows in natural sedimentary environments. However, at flow velocities above $1 \mathrm{~m} \mathrm{~s}^{-1}$, clay concentrations of at least $6 \%$ are required in order for flows to enter the transitional flow phase, but even at these velocities the transitional flow phases make up a significant proportion of the flow phase space. By converting the experimental data to nondimensional Froude number (momentum term) and Reynolds number (cohesive term), it is shown that
\end{abstract}


each boundary between the turbulent, transitional, and laminar flow phases can be described by a specific narrow range of Reynolds numbers. Within the duration of the experiments, settling of clay particles occurred only in plug flows of low flow velocity (and low Froude number), when the flows lacked the strength to support the entire clay suspension load. 


\section{INTRODUCTION}

It has been known since the pioneering work of Bagnold (1954) that the turbulence structure of flow can be altered if the volumetric concentration of suspended sediment is sufficiently large. In particular, the process of turbulence suppression in high-concentration flows with non-Newtonian, (pseudo-)plastic rheology has been widely adopted by the sedimentological community. Examples of flows in which turbulence has been assumed to be weakened, or suppressed entirely, are subaqueous mudflows and highdensity turbidity currents in lakes and seas (e.g., Middleton 1967; Lowe 1982; Mohrig et al. 1999; Lowe and Guy 2000), hyperconcentrated flows and subaerial mudflows in rivers (e.g., Wan and Wang 1994, Coussot 1995, 1997; Coussot and Meunier 1996), lahars in volcanic environments (e.g., Pierson and Scott 1985; Best 1992; Major et al. 1996; Lavigne and Thouret 2000) and mobile fluid muds in estuarine and shelf environments (e.g., Traykovski et al. 2000; Winterwerp and Van Kesteren 2004). Many of these types of flow are catastrophic in nature, and their deposits constitute an important part of the geological record, thus providing key reasons for gaining a better understanding of their internal structure and driving mechanisms. However, such studies are rare, even in the laboratory, mainly because of technical problems of data acquisition in opaque, high-concentration flows. Therefore, most present knowledge of these flows is based on conceptual models that lack quantitative support. These models assume a rapid attenuation of turbulence intensity as the concentration of sediment particles increases (e.g., Mulder and Alexander 2001; Winterwerp and Van Kesteren 2004). However, this assumption has been challenged for flows laden with cohesive clay particles, as shown by experimental work using montmorillonite clay (Wang and Larsen 1994; Wang and Plate 1996; Wang et al. 1998), and by more recent laboratory flume experiments with kaolinite clay (Baas and Best 2002, 2008).

Wang and Plate (1996) introduced the term "transitional flow" for flows with a transient turbulent behavior. These transitional flows are characterized by strong turbulence in a region near the bed and weak, or a total lack of, turbulence in a laminar layer immediately above the bed and in the upper layer within the outer flow region. Baas and Best (2002) investigated the dynamic structure of kaolin-laden, unidirectional flows moving over a fixed, smooth bed at a depth-averaged velocity of $\sim 0.33 \mathrm{~m} \mathrm{~s}^{-1}$. They found that the turbulence structure of the clay flows was modulated in a distinctive, previously largely unknown, manner at a volumetric sediment concentration between $\sim 2 \%$ and $\sim 4 \%$. The flows within this concentration range 
resembled the transitional flows of Wang and Plate (1996). Transitional flows of relatively low density were characterized by strong enhancement of near-bed turbulence, inferred to result from the development of a highly turbulent internal shear layer that separated a lower zone of high vertical gradient in downstream velocity from an upper zone in which that gradient was strongly reduced. Turbulence intensities in the upper zone were found to be reduced compared to equivalent turbulent flows of low density, and Baas and Best (2002) speculated that this reduction was due to the formation of cohesive electrostatic bonds between clay particles that prevented the upward dispersion of turbulent eddies. Relatively high-density transitional flows were described as plug flows, in which a rigid fluid mass lacking turbulence moves over a shear layer with reduced turbulence intensity (Baas and Best 2002). Wang and Plate (1996) and Baas and Best (2002) suggested that it becomes increasingly difficult to break up the cohesive bonds between particles as clay concentration increases within a transitional plug flow, until a pervasive network of permanently interlinked clay particles is formed, all turbulent energy is dissipated by the high effective viscosity, and the flow becomes laminar.

It is evident from the work of Wang and Plate (1996) and Baas and Best (2002) that the dynamic structure of transitional clay flows is more complex than the existing conceptual models portray. Furthermore, the concentrations at which the transitional flows were stable are wide-ranging and well within the reach of many natural clay flows. It should be emphasized, however, that the present knowledge of transitional flow behavior is based on a severely limited set of flow conditions, and that a wider range of flow conditions is required to fully justify the essential step to identifying transitional flow behavior and its signature in sedimentary deposits under natural conditions. It may be expected that the boundary conditions for transitional flow are controlled predominantly by applied stress, bed roughness (induced by grains and bedforms), flow viscosity, and yield strength (related to, for example, clay type and the admixture of noncohesive silt and sand; see Li and Gust 2000). The main objective of the present study was to determine how the dynamic structure of transitional flows is affected by changes in flow velocity, thus expanding the work of Baas and Best (2002). This was achieved by investigating the changing turbulence structure of kaolinite flows in a comprehensive set of laboratory experiments. Depth-averaged volumetric clay concentration and flow velocity ranged from $0.03 \%$ to $16.7 \%$ and from $0.13 \mathrm{~m} \mathrm{~s}^{-1}$ to $1.47 \mathrm{~m} \mathrm{~s}^{-1}$, respectively, thus simulating a large number of possible flow conditions in natural clay flows. 
The specific objectives of the experiments were: (1) to verify if the turbulence enhancement and plugflow development typical of the transitional flows of Baas and Best (2002) occurs over a wider range of flow velocities; (2) to determine how the threshold clay concentrations for possible transitional flow behavior change with changing flow velocity; and (3) to construct flow phase diagrams that can be used to delineate the stability regimes of turbulent, transitional, and laminar clay flows. Several examples are given of how these phase diagrams can be applied to the analysis of natural clay-laden currents.

\section{METHODOLOGY}

The laboratory methods used in the present study were similar to those of Baas and Best (2002), but with several notable modifications. Mixtures of pure kaolinite (median particle size: $0.009 \mathrm{~mm}$ ) and fresh water were circulated through a hydraulic flume by means of a variable-discharge slurry pump with a nondestructive centrifugal screw mechanism (Fig. 1). The flume was $8.75 \mathrm{~m}$ long and $0.3 \mathrm{~m}$ wide. At the upstream end of the flume, each flow moved underneath a wooden board set flush with the water surface, through a turbulence-damping grid and then through a horizontal stack of pipes, in order to straighten flow at the inlet. Downstream of the pipe stack, the flows moved over a flat, smooth, acrylic plastic floor. The section in which most data were collected was located $\sim 5.9 \mathrm{~m}$ from the flume inlet.

One hundred and eighty-two experiments were conducted to examine the dynamics of turbulent, transitional, and laminar flows at different combinations of downstream velocity and suspended clay concentration (Table 1). Each flow was steady and uniform, with a constant depth of between $0.13 \mathrm{~m}$ and $0.16 \mathrm{~m}$. The instantaneous component of horizontal flow velocity was measured using $2 \mathrm{MHz}$ and $4 \mathrm{MHz}$ ultrasonic Doppler velocity profilers (UDVP; see Takeda 1991; Best et al. 2001 for details) with a diameter of $8 \mathrm{~mm}$. UDVPs quantify flow velocity by determining the Doppler shift in ultrasound frequency as small particles pass through a measurement volume, and are particularly well suited for measuring velocities in opaque suspensions. Each UDVP acquired simultaneous velocity data along a profile of up to 128 points along the axis of the ultrasound beam, which in the present experiments extended up to $0.105 \mathrm{~m}$ from the probe head. No velocities were recorded in the proximal $0.012 \mathrm{~m}$, where the stagnation of flow by the UDVP was found to be unacceptably large. The $4 \mathrm{MHz}$ UDVPs were used at velocities up to $\sim 0.8 \mathrm{~m} \mathrm{~s}^{-1}$, whereas the $2 \mathrm{MHz}$ probes were better suited for higher velocities. 
In flows moving at up to $\sim 0.7 \mathrm{~m} \mathrm{~s}^{-1}$, a vertical array of four multiplexed UDVPs was used to measure the horizontal component of flow velocity, $u$, at closely spaced dimensionless heights $(z / h$, where $z$ is the height above the base and $h$ is the flow depth). At higher flow velocities, the probe array was found to impede flow through the measurement section, and a single UDVP was employed to solve this problem. Between measurements, the UDVP frame was shifted vertically in order to obtain velocity data at 16 different heights (between $\mathrm{z}=0.005 \mathrm{~m}$ and $\mathrm{z}=0.117 \mathrm{~m}$ ) in the low-velocity flows and at least 9 different heights (between $\mathrm{z}=$ $0.005 \mathrm{~m}$ and $\mathrm{z}=0.125 \mathrm{~m}$ ) in the high-velocity flows. The multiplexed UDVPs collected velocity data for durations of 109-165 s at a temporal resolution of 8-11 Hz. The corresponding limits for the single probe data were 51-121 s and 83-195 Hz, respectively (Table 1). The temporal mean flow velocity, $\bar{U}$, and its standard deviation, RMS $\left(u^{\prime}\right)$ (RMS is the root-mean-square and $u^{\prime}$ is a fluctuation in horizontal velocity, equal to $u-\bar{U}$ ) were calculated from the time series of instantaneous velocity data at each measurement height from:

$$
\begin{aligned}
& \bar{U}=\frac{1}{n} \sum_{i=1}^{n} u_{i} \\
& R M S\left(u^{\prime}\right)=\sqrt{\frac{1}{n} \sum_{i=1}^{n}\left(u_{i}-\bar{U}\right)^{2}}
\end{aligned}
$$

where $n$ is the number of velocity measurements. A dimensionless measure for turbulence intensity was defined as follows:

$$
R M S\left(u^{\prime}\right)_{0}=\frac{R M S\left(u^{\prime}\right)}{\bar{U}} \cdot 100
$$

For turbulent and part of the transitional flows, depth-averaged flow velocity, $\overline{\bar{U}}$, was computed using a curve-fitting procedure based on the logarithmic law of the wall (e.g., Van Rijn 1990):

$$
\overline{\bar{U}}=\frac{1}{h-z_{0}} \int_{z_{0}}^{h} \frac{u_{*}}{\kappa} \ln \left(\frac{z}{z_{0}}\right) d z
$$

where $u_{*}$ is the shear velocity, $\kappa$ is the von Kármán constant $(\kappa=0.4)$ and $z_{0}$ is the reference height at which $\bar{U}=0$. Equation 3 cannot be used for clay flows with strongly modulated turbulence, because the velocity profile of these flows deviates from a logarithmic curve (Fig. 2). Instead, $\overline{\bar{U}}$ values for laminar and several transitional flows were calculated using the Coles wake function (Coles 1956; Wang and Plate 1996; Wang et al. 2001): 


$$
\overline{\bar{U}}=\frac{1}{h-z_{0}} \int_{z_{0}}^{h}\left(\bar{U}_{\max }-\frac{u_{*}}{\kappa} \ln \left(\frac{h}{z}\right)-\frac{2 W u_{*}}{\kappa} \cos ^{2}\left(\frac{\pi z}{2 h}\right)\right) d z
$$

where $\bar{U}_{\max }$ is the maximum value of temporal mean velocity and $W$ is the wake strength coefficient. The von Kármán constant is assumed to be independent of clay concentration in Equation 4. In the present study, depth-averaged velocity ranged from $0.13 \mathrm{~m} \mathrm{~s}^{-1}$ to $1.47 \mathrm{~m} \mathrm{~s}^{-1}$ (Table 1).

At the end of each experiment, a vertical rack of five siphon tubes (internal diameter: 0.006 m) was used to collect suspension samples for measuring volumetric sediment concentration, $c$, through standard weighing and drying. Vertical concentration profiles show that suspended sediment was distributed uniformly through the water column (Fig. 3), except for depositional flows at low flow velocity and high clay concentration (e.g., Run 1-7), as discussed below. Depth-averaged concentration, C, (Table 1) calculated from the arithmetic mean of the concentration measurements, ranged from $0.03 \%$ to $16.7 \%$. Following Wan (1982). the dynamic viscosity, $\eta$, of the kaolinite suspensions was approximated from the measured suspended-sediment concentrations as follows:

$$
\eta=0.001+0.206\left(\frac{C}{100}\right)^{1.68}
$$

\section{PROFILES OF VELOCITY AND TURBULENCE INTENSITY}

\section{Results}

Vertical profiles of downstream velocity $(\bar{U})$, root-mean-square of downstream velocity (RMS $\left(u^{\prime}\right)$; Equation 1) and dimensionless turbulence intensity (RMS $\left(u^{\prime}\right)_{0}$; Equation 2) reveal systematic changes in the dynamics of fluid flow as suspended clay concentration increases. With very few exceptions, described below, the order of these changes was independent of velocity, with flow velocity merely controlling the clay concentration at which each change takes place. Figures 4 to 7 show characteristic vertical profiles of $\bar{U}$, $\operatorname{RMS}\left(u^{\prime}\right)$ and $\operatorname{RMS}\left(u^{\prime}\right)_{0}$ for different narrow velocity ranges and for sets of clay concentration that represent the variety of flows in each velocity range. 
Figure 4 depicts profiles of velocity and turbulence intensity for flows with a low depth-averaged velocity $\left(\overline{\bar{U}}=0.129-0.172 \mathrm{~m} \mathrm{~s}^{-1}\right)$ and a progressive increase in concentration from $0.04 \%$ to $5.33 \%$ (Table 1$)$. The profiles for the flow carrying $0.04 \%$ kaolinite are characteristic of a turbulent, wall-bounded shear flow (e.g., Nezu and Nakagawa 1993), and exhibit a logarithmic increase in velocity and a logarithmic decrease in dimensionless turbulence intensity with increasing height above the bed. At $C=0.34 \%$ and $C=0.74 \%$, the velocity profile retained its logarithmic shape, as supported by statistical goodness-of-fit calculations, yet velocities progressively diminish, particularly close to the base of the flow (e.g., at $z / h=0.03$ in Figure 4A). This change closely resembles the evolution from turbulent to transitional flow behavior sensu Baas and Best (2002). The decreasing near-bed velocity is accompanied by a progressive increase in RMS( $\left.u^{\prime}\right)$ and RMS $\left(u^{\prime}\right)_{0}$, again in agreement with previous laboratory results (Wang and Plate 1996; Baas and Best 2002). If it is assumed that the dilute flow with $C=0.04 \%$ is dynamically similar to a clay-free flow, turbulence enhancement should start between $C=0.04$ and $C=0.34 \%$ for the range in flow velocity shown in Figure 4 . The trends of decreasing near-bed flow velocity and increasing turbulence intensity persist until at $C=$ $2.32 \%$ the near-bed downstream velocity is close to zero, and consequently RMS $\left(u^{\prime}\right)_{0}$ reaches a high maximum value (Fig. 4C). Upon further addition of kaolinite, part of the clay begins to settle out of suspension, thus burying the UDVP at $z / h \approx 0.03$ within the typical flow duration of $\sim 20$ minutes. Clay also settled in flows moving at $\sim 0.3 \mathrm{~m} \mathrm{~s}^{-1}$, but deposition appeared to be lacking within the duration of the experiments at velocities greater than $\sim 0.4 \mathrm{~m} \mathrm{~s}^{-1}$. Another distinctive change in flow structure is the gradual development of a plug flow, as implied by the progressive expansion of a zone of low velocity gradient and low turbulence intensity from the top of the flow downward, until velocity and turbulence intensity are almost invariant with depth within the upper $80 \%$ of the $5.33 \%$ clay flow. At this clay concentration, RMS $\left(u^{\prime}\right)$ directly above the deposit is less than in any other flow in the selected velocity range. Nonetheless, RMS $\left(u^{\prime}\right)$ is only half of the mean downstream velocity, thus suggesting that the flow remained weakly turbulent below the plug-flow region. The flow carrying 3.18\% kaolinite is unique in the sense that maximum RMS $\left(u^{\prime}\right)$ occurs at $z / h=0.09$ instead of at the base of the flow (Figure 4B; see also Figure 2C of Baas and Best 2002).

Figure 5 shows profiles of velocity and turbulence for selected flows ranging in mean velocity from 0.405 $\mathrm{m} \mathrm{s}^{-1}$ to $0.451 \mathrm{~m} \mathrm{~s}^{-1}$. These velocities were high enough to prevent clay from settling within the duration of the experiments, even at concentrations of $14.47 \%$. Otherwise, the flows evolved in a manner similar to 
those of lower velocity, described above. This includes the progressive deceleration of near-bed velocity, the initial enhancement of near-bed turbulence, and the subsequent development of a plug-flow region moving over a thin layer of fluid with attenuated $\operatorname{RMS}\left(u^{\prime}\right)$ at $C>7.43 \%$ (e.g., run 3-22 in Figure 5). At these higher velocities, the boundaries between the different flow phases are seen to shift to higher clay concentrations. It is remarkable that turbulence enhancement commences at concentrations as low as $\sim 0.26 \%$, and that the flows carrying $5.45 \%$ and $7.43 \%$ are significantly more turbulent than flows of lower concentration, both near the bed and across the rest of the flow depth (Figs. 5B,C).

Figures 6 and 7 illustrate the changing velocity structure within high-concentration clay flows with $\overline{\bar{U}}=$ 0.879-0.940 $\mathrm{m} \mathrm{s}^{-1}$ and $\overline{\bar{U}}=1.245-1.433 \mathrm{~m} \mathrm{~s}^{-1}$, respectively. In these flows, the different stages of plug-flow development are particularly well defined. In Figures 6B and 6C, for example, the base of the plug is positioned at $z / h \approx 0.7$ in the $11.53 \%$ clay flow, and expands to $z / h \approx 0.6$ at $C=12.46 \%$ and then to $z / h \approx 0.4$ at $C=13.09 \%$. The plug finally reaches down to $z / h \approx 0.2$ in the flow carrying $15.34 \%$ kaolinite. These concentration-induced changes in dynamic flow structure in the high-velocity flows largely mirror those found in the lower-velocity flows described above, although with two notable exceptions. First, turbulent flows lacking near-bed flow deceleration and turbulence enhancement span an increasingly wider range of concentrations in flows with $\overline{\bar{U}}>0.5 \mathrm{~m} \mathrm{~s}^{-1}$, whereas these changes in near-bed flow structure start consistently below $C \approx 0.75 \%$ at $\overline{\bar{U}}<0.5 \mathrm{~m} \mathrm{~s}^{-1}$. In fast moving flows $\left(\overline{\bar{U}}>0.9 \mathrm{~m} \mathrm{~s}^{-1}\right)$, turbulence modulation does not begin before the clay concentration reaches $5 \%$. Second, at all flow velocities greater than $\sim 0.8 \mathrm{~m} \mathrm{~s}^{-}$

${ }^{1}$, the shift in maximum RMS $\left(u^{\prime}\right)$ away from the bed persists after the plug is fully developed. At $\overline{\bar{U}}<0.8 \mathrm{~m}$ $\mathrm{s}^{-1}$, however, maximum RMS $\left(u^{\prime}\right)$ shifts back to the base of the flow well before the plug reaches its maximum thickness.

\section{Definition of Flow Phases}

The experimental data presented herein reveal that the dynamic properties of clay-laden flows moving over a flat boundary are strongly dependent on clay concentration, with the changes in dynamic structure being predictable and largely independent of flow velocity. Five different flow phases can be defined within the studied range of clay concentrations. These phases are, in order of increasing clay concentration: (1) 
turbulent flow; (2) turbulence-enhanced transitional flow; (3) lower transitional plug flow; (4) upper transitional plug flow; and (5) quasi-laminar plug flow. Each flow phase holds unique properties. The turbulent flow is characterized by logarithmic profiles of downstream velocity that obey the law of the wall for clay-free flows. In this phase, RMS $\left(u^{\prime}\right)_{0}$ decreases gradually as height above the bed increases. In the turbulence-enhanced transitional flow, velocity decreases and turbulence intensity increases with increasing clay concentration across the entire flow depth, while retaining the logarithmic relationship with flow height. This is in contrast to the lower transitional plug flow, in which the velocity profile is described best by the Coles wake function (Equation 4), because of the combined effect of decreasing near-bed velocity, increasing near-bed turbulence, decreasing turbulence in the outer flow, and initial plug-flow development. The boundary between lower and upper transitional plug flow is defined at the clay concentration where maximum values of near-bed RMS $\left(u^{\prime}\right)_{0}$ are attained. As clay concentration increases within the upper transitional plug flow, the plug-flow region gradually grows to its maximum thickness, near-bed velocity continues to decrease, and turbulence intensity rapidly decreases. Initially, maximum RMS $\left(u^{\prime}\right)$ is present at the lowest measurement height, i.e., at $z / h \approx 0.03$. Thereafter, maximum RMS( $u$ ') moves away from the bed to $\mathrm{z} / \mathrm{h} \approx 0.1$. Lastly, the quasi-laminar plug flow is characterized by a laminar plug flow region moving on a thin shear layer. The shear layer has a steep velocity gradient and usually possesses some residual turbulence. The highest RMS( $\left.u^{\prime}\right)$ values are present at the top of the shear layer in the high-velocity quasilaminar plug flow, whereas in the low-velocity equivalents the location of maximum RMS $\left(u^{\prime}\right)$ shifts to lower heights.

The fact that nearly all flows go through the same development stages, regardless of their velocity, renders it possible to define standard profiles for velocity and turbulence intensity using simple dimensionless parameters. In each flow phase, the velocity and turbulence data collapse well using relative temporal mean velocity, $\bar{U} / \bar{U}_{\max }$ and dimensionless turbulence intensity, RMS $\left(u^{\prime}\right)_{0}$, plotted against dimensionless height, $z / h$ (Fig. 8). Figure 8 shows the mean, standard deviation, and range of $\bar{U} / \bar{U}_{\max }$ and $\operatorname{RMS}\left(u^{\prime}\right)_{0}$ versus $z / h$, as well as best-fit equations, for turbulent flow (Fig. 8A), turbulence-enhanced transitional flow (Fig. 8B), lower and upper transitional plug flow (Figs 8C and 8D), and quasi-laminar plug flow (Fig. 8E). $\bar{U} / \bar{U}_{\max }$ and RMS $\left(u^{\prime}\right)_{0}$ for all turbulent flows collapse onto single logarithmic curves with high coefficients of determination $\left(R^{2}\right.$ values in Figure 8A), with the regression line for turbulent flows also 
being shown for comparison in Figures 8B-E. Since the transitional flow types are subject to progressive change in flow properties, albeit in a similar dimensionless way for each velocity, each best-fit equation should be regarded as the average for the transitional flow phase for which it was computed. This explains the typically wide range of velocity and turbulence data in Figure 8, particularly near the base of the transitional flow curves.

\section{Interpretation of Changing Flow Dynamics}

Many clays suspended in water, including kaolinite, have cohesive properties, because molecular-scale, electrostatic forces cause the particles to attract each other (e.g., Van Olphen 1977). The degree of cohesion is dependent on the distribution of electrical charges at the particle surface, the distance between the particles, and the fluid medium (e.g., fresh or saline water). The surface charge in turn is governed by chemical composition, and hence by the type of clay. Two clay particles may collide and form a larger particle, or floc, when the distance between the particles is sufficiently small (Krone 1963; Kranenburg 1994; Merkelbach and Kranenburg 2004; Winterwerp and Van Kesteren 2004). Flocculation continues, and flocs grow in size, until the number of particles becomes so small that the probability of particles colliding with each other becomes negligible. Floc size tends to increase with increasing bulk suspended clay concentration until the "gelling" point is reached, which is characterized by formation of a pervasive, volume-filling network of particle bonds in the liquid. The particle bonds within gels can make a flow viscous and be strong enough to cause the total suppression of turbulence in flowing clay suspensions. Alternatively, the bonds between clay particles in flocs and gels can be broken if turbulence within the flow is sufficiently strong (e.g., Winterwerp and Van Kesteren 2004), in a process called de-flocculation. There is thus a close interaction between turbulent and cohesive forces that controls the dynamic structure of clay flows. Because turbulence may be generated by shear at flow boundaries (e.g., the near-bed boundary layer) and within the flow (e.g., free shear layers), it is essential to determine how the interplay between turbulent and cohesive forces affects different regions within a flow. In the present experiments, cohesive forces were controlled merely by clay concentration, because only one clay type (kaolinite) was used. Flocculation and gelling may thus be expected to dominate at heights where turbulence intensities are low and clay concentration is high, therefore resulting in a more laminar flow behavior. Conversely, flocculation and gelling should be reduced 
or absent in areas of strong turbulence and low clay concentration, where a more turbulent flow behavior may be expected to prevail. At locations in which both turbulence and cohesion contribute significantly to the flow dynamics, this force balance will dictate if, and how, turbulence modulates flow rheology and vice versa. Flows that are transitional in behavior between Newtonian turbulent and non-Newtonian laminar may form under such conditions.

It is evident from the UDVP data in the present smooth, flat-bed, boundary-layer flows that turbulence is generated near the bed in the turbulent flows, with turbulence intensity gradually decreasing away from the boundary (Fig. 9A). This bed-generated turbulence continues to be important as clay concentration increases through the transitional flow phases. Even in the quasi-laminar flows, the weak, yet distinct, velocity fluctuations captured in the RMS( $\left(u^{\prime}\right)$ data (Fig. 9E) suggest that some residual turbulence is generated at the bed.

$\operatorname{RMS}\left(u^{\prime}\right)_{0}$ in the turbulence-enhanced transitional flows is on average $17 \%$ higher than in the turbulent flows (Fig. 8B). The origin of this large increase must lie in the higher clay concentration in the turbulenceenhanced turbulent flows, since concentration is the only variable that distinguishes these two flow phases. It is known that the physical presence of suspended sediment can cause modifications in dynamic flow structure via either damping or enhancing turbulence at low and high ratios of particle diameter to turbulence length scale, respectively (Gore and Crowe 1989; Elgobashi 1994; Best et al. 1997). Elgobashi (1994) investigated turbulence modulation as a function of sediment concentration and the ratio between particle response time, $t_{p}$ (i.e., the ratio between settling velocity and reduced gravity) and the turnover time of a turbulent eddy, $t_{e}$ (i.e., the ratio between eddy length and RMS fluid velocity). Above a lower threshold concentration, particles are thought to dissipate turbulent energy if $t_{p} / t_{e}<1$, but produce additional turbulent energy by wake shedding and inertial effects if $t_{p} / t_{e}>1$. Moreover, Best (1998) showed how grain rotation may enhance turbulence production around grains at low particle Reynolds numbers. However, according to the model of Elgobashi (1994), above an upper threshold concentration particle interactions become dominant and turbulence is suppressed (cf. Bagnold 1954). Elgobashi (1994) based the boundaries between these regimes on data from gas flows, but the general principles of the model may also apply to water flows. Settling velocity is part of the numerator of particle response time, and hence small particles have a shorter response time than larger particles. Consequently, between the above threshold concentrations in many aqueous flows, sand and gravel grains will generate turbulence enhancement, whereas clay and silt particles 
should favor turbulence attenuation. Neither sand nor gravel was present in the turbulence-enhanced transitional clay flows, so wake shedding and grain rotation can be ruled out as mechanisms responsible for the high turbulence intensities measured. An alternative mechanism for turbulence enhancement, through the development of a near-bed internal shear layer, is described below.

Figures 9C and 9D show schematically how the near-bed flow structure and the plug-flow region evolve as a function of clay concentration in the lower and upper transitional plug flows. Initially, the vertical gradient of turbulence intensity increases dramatically, with very strong turbulence near the bed and development of a relatively thin plug flow almost devoid of turbulence near the top of the flow. It is inferred that turbulence induced by shear at the bed is strong enough to withstand gelling of the clay suspension near the base of the flow. However, near the top of the flow the effect of bed shear is minimal (where the velocity gradient is smallest), and cohesive forces outbalance turbulent forces, because the high clay concentration prevents near-bed turbulent fluid from reaching this height. This thus results in gelling and formation of the plug flow. Within the remainder of the flow, no pervasive network of particle bonds exists, and turbulence is damped, but not fully suppressed. Maximum near-bed dimensionless turbulence intensity is reached at the boundary between the lower and upper transitional plug flow phases, where RMS $\left(u^{\prime}\right)$ typically is 65\% higher than in the turbulent flows. Within the upper transitional plug flows, cohesive forces become increasingly dominant over turbulent forces, which is expressed by decreasing RMS( $\left.u^{\prime}\right)$ in the entire flow and downward expansion of the plug-flow region. Moreover, the level of maximum RMS $\left(u^{\prime}\right)$ moves away from the bed. Baas and Best (2002) explained this upward shift in turbulence production through the presence of an internal shear layer that separates a near-bed region with steep velocity gradient from the plug-flow region with a lower velocity gradient. Kelvin-Helmholtz instabilities were proposed as the principal source of turbulence within the shear layer. Wang and Plate (1996) showed that the height of maximum turbulence intensity within transitional flows gradually moves away from the bed with increasing clay concentration as a result of expansion of what they termed a laminar sublayer. In low-density and highdensity flows, Wang and Plate (1996) found the region of maximum turbulence at $z<0.5 \mathrm{~mm}(\mathrm{z} / \mathrm{h}<0.05)$ and $z=8 \mathrm{~mm}(\mathrm{z} / \mathrm{h}=0.2)$, respectively, which is of the same order of magnitude as in the present study (Figs 4-7). However, the vertical resolution in the present study is insufficient to establish a similar relationship between concentration and the height of maximum turbulence. The level of maximum turbulence intensity (and thus the internal shear layer) in the lower transitional plug flows may well have been located closer to 
the bed than in the upper transitional plug flows. It can also be speculated that the increased turbulence production in the turbulence-enhanced transitional flows may be caused by an internal shear layer well below the lowermost UDVP probe, instead of by wake shedding behind clay flocs (see above). Upward dispersion of the stronger turbulent eddies from this shear layer may then explain the increased turbulence in the middle and upper regions of the turbulence-enhanced transitional flows. Such reduction of the near-wall velocity gradient and growth of a viscous sublayer was also found in drag-reducing flows containing kaolinite by Best and Leeder (1993) and Li and Gust (2000). Furthermore, Best and Leeder (1993) recorded an increase in the height of the turbulence maximum above the bed with thickening of the viscous sublayer, and this finds parallels in the trends found in the present experiments.

Under conditions of quasi-laminar plug flow, the yield stress within most of the flow is high enough to prevent any turbulence from breaking up the electrostatic bonds between clay particles, except perhaps near the bed where the gel is occasionally broken up by minor bed-generated turbulence. This results in a thick rigid plug moving over a thin shear layer that is predominantly laminar but occasionally becomes weakly turbulent (Fig. 9E).

\section{EXPRESSION OF FLOW PHASES IN VELOCITY TIME SERIES}

Each clay flow phase comprises unique time series of the horizontal component of flow velocity, with progressive changes in the character of these time series being a function of both clay concentration and height above the bed. Representative examples of these time series for each flow phase are provided below.

In the turbulent flows, the time series of downstream velocity are characterized by quasi-random velocity fluctuations at time-scales ranging from several tenths of a second to several seconds (Fig. 10A). The amplitude of the velocity fluctuations decreases with increasing height above the bed, but there are no obvious changes in their frequency distribution. The time series of the turbulence-enhanced transitional flows are largely similar to those of the turbulent flows, although there is some organization of sub-secondscale velocity fluctuations superimposed on the rising and falling limbs of second-scale fluctuations (e.g., at $\mathrm{z} / \mathrm{h}=0.03$ in Figure 10B).

With the development of the incipient plug flow in the lower transitional plug flows (Fig. 11), the amplitude of velocity fluctuations near the top of the flow becomes small (typically only $4 \%$ of the mean 
downstream velocity), with periodicities almost exclusively at a sub-second scale. The amplitude of velocity fluctuations near the bed continues to rise, thus explaining the high $\operatorname{RMS}\left(u^{\prime}\right)$ and $\operatorname{RMS}\left(u^{\prime}\right)_{0}$ values at that location. Most remarkable, however, is the development of a regular pattern of asymmetrical "saw-tooth"shaped velocity fluctuations (cf. Baas and Best 2002), which consist of a phase of rapid flow acceleration followed by a longer phase of flow deceleration, with a periodicity of up to $10 \mathrm{~s}$ (Fig. 11). The saw-tooth patterns are most evident in the upper part of the lower transitional plug flows, where large-amplitude, highfrequency velocity fluctuations, which partly obscure the longer-term trends in the lower part of that flow phase, are rare. Thus, sub-second-scale velocity fluctuations are gradually suppressed as concentration increases within the lower transitional plug flows, while second-scale fluctuations persist (cf. Wang and Plate 1996). Figure 12 shows the evolution of selected near-bed velocity time series $(\mathrm{z} / \mathrm{h} \approx 0.03)$ as a function of concentration in supercritical flows $(\mathrm{Fr}>1)$ with $\overline{\bar{U}} \approx 1.4-1.5 \mathrm{~m} \mathrm{~s}^{-1}$. The partial obscuration of the sawtooth patterns is confirmed by the time series of the flow with $14.45 \%$ kaolinite. At progressively higher clay concentrations, the frequency and amplitude of the asymmetrical velocity fluctuations gradually decreases, until rare, weak fluctuations punctuate a pattern of nearly constant velocity at $C=16.67 \%$. Baas and Best (2002) proposed that the near-bed, asymmetric, saw-tooth-shaped velocity fluctuations are caused by KelvinHelmholtz instabilities associated with an internal shear layer present within the lower part of transitional clay flows (Fig. 13). In their model, velocity time series at $z / h>0.30$ are characterized by short negative excursions in downstream velocity that interrupt a trend of more or less constant velocity. The spikes of lowdownstream-velocity fluid were shown to correlate with upward-directed components of vertical velocity. This led Baas and Best (2002) to conclude that packets of low-velocity fluid are periodically shed as KelvinHelmholtz instabilities off the top of the internal shear layer, and advected into the outer flow region, where they gradually dissipate. Similar low-velocity packets were found in the present study (e.g., at $z / h=0.43$ in Figure 11A and $z / h=0.21$ in Figure 11B) and also support the earlier findings of Wang and Plate (1996). The alternation of periods of low and high velocity at intermediate heights (e.g., at $z / h=0.11$ in Figures $11 \mathrm{~A}$, B) also agrees with the model of transitional flow proposed by Baas and Best (2002). Considering the wider range of flow conditions investigated herein, it can be concluded that an internal shear layer possessing Kelvin-Helmholtz instabilities is a universal feature of lower transitional plug flows. 
Flows with an internal shear layer in their lower region span the boundary between the lower and upper transitional plug flow (Fig. 12). Across this boundary, the shear layer appears to move away from the bed, as the level of maximum $\operatorname{RMS}\left(u^{\prime}\right)$ shifts from $z / h=0.03$ to $z / h \approx 0.06$ in low-velocity runs $\left(\overline{\bar{U}}<0.8 \mathrm{~m} \mathrm{~s}^{-1}\right)$ and to $\mathrm{z} / \mathrm{h} \approx 0.10$ in high-velocity runs $\left(\overline{\bar{U}}>0.8 \mathrm{~m} \mathrm{~s}^{-1}\right)$. Figure $14 \mathrm{~A}$ shows that long-period velocity fluctuations are present in the lower region of the upper transitional plug flows. The amplitude of these fluctuations increases slightly with height above the bed to $\mathrm{z} / \mathrm{h} \approx 0.10$. In the remainder of the flow, both the amplitude and periodicity of the fluctuations gradually decrease away from the bed until they disappear altogether when entering the plug region. No appreciable sub-second-scale velocity fluctuations are present in the time series of upper transitional plug flows, because the small eddies that cause the fluctuations are quickly attenuated by the viscous flow in this flow phase. In the quasi-laminar plug flows, even the long-term velocity fluctuations have disappeared and the downstream flow component is more or less constant due to the strong network of clay particles (Fig. 14B).

\section{FLOW PHASE DIAGRAMS}

\section{Dimensional Plot of Velocity Against Concentration}

Depth-averaged flow velocity and clay concentration are the principal physical parameters that control the dynamics of clay flows in the present study. In general, the boundaries between the turbulent, transitional and laminar flow phases move to higher clay concentrations as depth-averaged velocity increases. At these higher velocities, turbulence generated by boundary shear becomes greater and the flows are able to prevent flocculation and gelling. In order to allow predictions to be made of the internal dynamics of clay flows, the

position of the phase boundaries has been plotted in phase diagrams that contain all the experimental data of depth-averaged flow velocity (derived from Equations 3 and 4) versus depth-averaged kaolinite concentration (Fig. 15). An additional boundary on the left hand side of Figure 15 separates depositional from nondepositional clay flows.

Figure 15A clearly shows that transitional flows occupy the greater part of the phase diagram, and that most transitional clay flows in the range from $\sim 0.2 \mathrm{~m} \mathrm{~s}^{-1}$ to $\sim 0.8 \mathrm{~m} \mathrm{~s}^{-1}$ are turbulence-enhanced. In fact, 
below $\overline{\bar{U}}=0.4 \mathrm{~m} \mathrm{~s}^{-1}$ “classical” turbulent flows are expected to occur only in flows with clay concentrations of much less than one percent (see Figure 15B). The turbulent flows are dominant above $\sim 0.8 \mathrm{~m} \mathrm{~s}{ }^{-1}$, but even here transitional and laminar flows occupy a significant area of the phase diagram. The lower transitional plug flows are stable across a wider range of concentrations than the upper transitional plug flows. This effectively means that once a transitional plug flow has reached its maximum near-bed turbulence intensity, adding more clay quickly results in quasi-laminar flow behavior, as exemplified for flows moving at 0.40-0.45 $\mathrm{m} \mathrm{s}^{-1}$ and $0.94-1.05 \mathrm{~m} \mathrm{~s}^{-1}$ (Fig. 16).

The depositional phase comprises flows that do not have sufficient strength to support the entire clay suspension load within the duration of the experiments. The high gradient of the line separating the depositional phase from nondepositional phases (Fig. 15) implies that flows with velocities higher than $\sim 0.4$ $\mathrm{m} \mathrm{s}^{-1}$ are likely to be stable within the duration of the experiments, except perhaps at clay concentrations and flow durations that are well above the maximum values used in the present study. A progressive decrease in clay concentration due to deposition is accompanied by a change in internal flow structure until new equilibrium conditions are reached. Further experimental work is required to obtain a better understanding of the changing dynamics of such depositional clay flows with time-varying transient behavior.

\section{Dimensionless Phase Diagram using Froude and Reynolds Numbers}

Figure 17 presents the experimental data collected in the present study in dimensionless form, using the Froude number, Fr, and the flow Reynolds number, Re, which represent momentum and cohesive terms, respectively. The Froude number is given by

$$
F r=\frac{\overline{\bar{U}}}{\sqrt{g h}}
$$

where $\overline{\bar{U}}$ is the depth-averaged flow velocity, $h$ is the flow depth, and $g$ is the acceleration due to gravity

(Table 1). The Reynolds number was calculated from (Migniot, 1968, 1989; Ricardo Silva-Jacinto, personal communication):

$$
R e=\frac{\overline{\bar{U}}_{z_{p}} \rho}{\eta}
$$


where $\rho$ is the flow density, $\eta$ is the dynamic viscosity of the flow, and $z_{p}$ is the thickness of the flow region below the base of the plug flow. In Equation $7, z_{p}$ is used instead of flow depth, because the largest length scales of turbulence within the transitional and laminar clay flows are limited by the distance between the lower flow boundary and the base of the plug-flow region (Ricardo Silva-Jacinto, personal communication). In other words, at a specific boundary shear and flow viscosity, the position of the base of the plug flow region is considered to be independent of the flow depth, because turbulent energy cannot extend to $z>z_{p}$. In turbulent flows and turbulence-enhanced transitional flows, in which plug-flow regions are absent, the following length scale is used in Equation 7:

$$
z_{p}=h
$$

In Figure 17, the phase boundaries for all flow types are given by a narrow range of Reynolds numbers, which suggests that the changing balance between turbulent and cohesive forces is captured well for the studied range of Froude numbers. The mean Reynolds number for the boundary between turbulent flow and turbulence-enhanced transitional flow is 55,000 (standard deviation: 20,000), while lower transitional plug flow falls between $\operatorname{Re}=12000$ (standard deviation: 3400) and 28,100 (standard deviation: 6100). The boundary between upper transitional plug flow and quasi-laminar flow is at $\mathrm{Re}=7000$ (standard deviation: 2400). The variation in mean Reynolds number, given by the standard deviation, may be caused by uncertainties in the viscosity model used for the present experiments.

The experimental data of Wang and Plate (1996; for all flows deeper than $0.03 \mathrm{~m}$ ) are used to plot a Fr-Re phase diagram for turbulent, transitional, and laminar montmorillonite clay flows in Figure 18. Although Wang and Plate (1996) defined only one type of transitional flow and no turbulence-enhanced flow type, there is sufficient correspondence between the montmorillonite and kaolinite datasets to suggest that the Froude and Reynolds number criteria, as given in Equations 6 and 7, are suitable dimensionless parameters to collapse datasets based on clay types with different rheological properties. Specifically, the phase boundary between turbulent and transitional montmorillonite flow lies between $\mathrm{Re}=12,000$ and $\mathrm{Re}=$ 40,000, which corresponds reasonably well with the boundary between the turbulence-enhanced transitional flow and the lower transitional plug flow phases in kaolinite-laden flows $(\operatorname{Re}=28,100 \pm 6100)$. Moreover, the phase boundary between transitional and laminar montmorillonite flow is mimicked in the present kaolinite flows by the boundary between upper transitional plug flow and quasi-laminar plug flow (i.e., $\mathrm{Re}=$ $7000 \pm 2400$ for the kaolinite flows versus $\mathrm{Re} \approx 5500$ for the montmorillonite flows). The distinct vertical 
separation of flow types for the montmorillonite clay at high Froude numbers (Fig. 18) substantiates the earlier conclusion that phase boundaries can be characterized by a single Reynolds number, or a narrow range of Re values, for all Froude numbers. In velocity-clay concentration space, such as Figure 15, the phase boundaries for montmorillonite flows would be at lower concentrations than the phase boundaries for kaolinite flows moving at the same velocity, because montmorillonite has a higher yield strength than kaolinite at any given concentration. In other words, montmorillonite-laden flows experience turbulence modulation at even lower concentration than kaolinite-laden flows.

\section{COMPARISON BETWEEN FLOWS IN THE LABORATORY AND IN NATURAL ENVIRONMENTS}

The flow phase diagrams proposed herein are based on laboratory experiments conducted with shallow, steady, uniform, fresh-water flows transporting pure kaolinite clay, moving over a fixed, smooth, flat bed. This is an oversimplification of most natural clay-laden flows in three principal aspects. Firstly, kaolinite has weaker cohesive strength than most other clay minerals, such as illite and smectite, which are thus likely to show transitional flow behavior at lower concentrations. The salinity of water in marine basins also promotes cohesion by aiding flocculation ( $\mathrm{Li}$ and Gust 2000), therefore also lowering the concentration required for

turbulence modulation. Secondly, the smooth, fixed beds used in the present experiments can be regarded as an analogue for erosion-resistant muddy surfaces formed by suspension settling. In contrast, increased turbulent mixing at loose boundaries with grain and bedform roughness may cause a shift in the phase boundaries shown in Figure 15A to higher concentrations (Wang et al. 1996). Lastly, natural flows typically transport mixtures of cohesive, noncohesive, and organic material, but the effect that such mixtures have on the fluid dynamics is poorly known at present (Wang and Larsen 1994). More experimental research is thus clearly required to permit accurate quantitative predictions of the dynamics of many natural clay-laden flows. However, from a qualitative point of view, valuable comparisons can be made, provided that these comparisons are conducted for flows with high ratios of clay to silt/sand. Baas and Best (2002) discussed possible implications of transitional flow dynamics for the depositional properties of these flows, such as presence or absence of vertical size grading and the origin of silt-mud couplets in turbidites. Here, the discussion focuses on the potential importance of transitional flows in natural environments through use of a 
selection of published data from various sedimentary environments and other laboratory flume data. The comparison with the present laboratory data is achieved by plotting data from past studies in the $\overline{\bar{U}}-C$ phase diagram, and by calculating Re values, where possible. The phase boundaries of quasi-laminar flow, upper transitional plug flow, and lower transitional plug flow are assumed to be independent of flow depth (Equation 7), but the Reynolds number for the boundary between turbulent flow and turbulence-enhanced transitional flow increases with increasing flow depth through Equations 7 and 8 . Hence, $\operatorname{Re}=55,000 \pm$ 20,000 can be regarded as a minimum value for the lower boundary of turbulence-enhanced transitional flow, since most natural flows are deeper than $0.15 \mathrm{~m}$, for which this Re value was determined.

The dominance of transitional flows at low flow velocities is important from two perspectives. First, the present experiments suggest that natural clay flows that move at $\leq \sim 0.4 \mathrm{~m} \mathrm{~s}^{-1}$ may experience turbulence enhancement at clay concentrations that would previously have been considered to have no effect on the flow dynamics. Second, even if a turbulent clay-laden flow moves at a higher velocity (or a high Froude number), it eventually decelerates and has a high probability of passing through the transitional flow phases, where it is subjected to turbulence modulation. Since the settling rate of clay particles is low, even if the clay settles en masse, decelerating flows are prone to be oversaturated with clay, which further increases the likelihood of turbulence modulation. Turbulence enhancement in the near-bed flow region may be accompanied by increased bed erosion, and thus by increased sediment transport rates and changes in bedform properties (Baas and Best 2008). Such increased bed erosion may result from the powerful, instantaneous velocity fluctuations produced in turbulence-enhanced transitional flows (Fig. 10B) and lower transitional plug flows (Fig. 10B), but also by a general increase in the mean bed shear stress, as calculated using energy slope, flow depth, and flow density, across the phase boundary between turbulent and turbulence-enhanced transitional flow (Table 1). These processes may be recorded as pronounced scour surfaces within sedimentary deposits.

The key question that arises is what proportion of natural clay-laden flows can be expected to experience transitional flow behavior. The motive for this question is that the dynamics of transitional flows may just be a curiosity if most natural flows do not contain enough clay to exhibit turbulence enhancement or damping. Traykovski et al. (2000) described a fluid-mud layer on the continental shelf off the Eel river estuary in California, which was formed by a gravitationally forced, bottom-hugging density flow moving out of the estuary during a flood event. The fluid-mud layer was between 0.05 and $0.15 \mathrm{~m}$ thick, sediment 
concentration within the layer was at least $0.8 \%$ and possibly up to $3 \%$ by volume, and it moved at a velocity of $\sim 0.3 \mathrm{~m} \mathrm{~s}^{-1}$. These conditions are likely within turbulence-enhanced transitional flow or lower transitional flow behavior (Figs 17 and 19), with Reynolds numbers ranging from 10,000 to 40,000 (using the viscosity of kaolinite as a first-order approximation). Traykovski et al. (2000) recognized waves at the top of the lutocline, which were speculated to arise through either Kelvin-Helmholtz instability or parametric resonance at this interface of steep vertical density gradient. The instabilities in the mobile fluid mud may be similar to those inferred to exist at the internal shear layer within transitional plug flows (Fig. 13). The fluidmud layer of Traykovski et al. (2000) plots in an area of the phase diagram where near-bed turbulence enhancement is expected to occur (Figs 17 and 19). If density currents, such as those recorded from the Eel river, do undergo turbulence enhancement, this may provide an additional mechanism to help maintain the flow momentum through erosion of bed sediment and subsequent increase in the density of the underflow, thus promoting autosuspension (cf. Parker et al. 1986).

Van Kessel and Kranenburg (1996) replicated mobile fluid muds in a sloping laboratory flume, using a series of kaolinite suspensions with concentrations between $2.2 \%$ and $14.6 \%$, flow velocities between $0.12 \mathrm{~m}$ $\mathrm{s}^{-1}$ and $0.34 \mathrm{~m} \mathrm{~s}^{-1}$ (Fig. 19), and flow depths between $0.025 \mathrm{~m}$ and $0.065 \mathrm{~m}$. Experimental and numerical data analyses showed that the flows changed from turbulent to laminar with plug flow regions at $C \approx 8.8 \%$. This sediment concentration agrees well with the boundary between the transitional plug flow and quasi-laminar plug flow phases, where turbulence was fully suppressed, in the present study. According to their position in the phase diagram, most low-density flows documented by Van Kessel and Kranenburg (1996) may have been turbulence-enhanced, in particular near to the bed. Corresponding Reynolds numbers, estimated using mean flow velocity, initial flow density and total flow depth, are of the order of 6000 to 14,000. These Re values are somewhat lower than expected, because of the relatively small depths of the experimental flows of Van Kessel and Kranenburg (1996). The high-density kaolinite flows of Kessel and Kranenburg (1996) plot in the depositional region (Fig. 19), but the short duration of the flows negates any significant effect of clay deposition on the dynamic flow structure. The base of the plug-flow region in one of these flows was present at $z_{p}=0.02 \mathrm{~m}$ (Figure 3B of Van Kessel and Kranenburg 1996). Using this height for all high-density flows in Equation 7 yields Reynolds numbers ranging from 400 to 600, and thus well within the laminar-flow phase space of Figure 17. 
Another kaolinite-laden density underflow was investigated by Felix et al. (2005). This flow was characterized by a high initial velocity, an initial clay concentration of $\sim 15.5 \%$, and a nondepositional character, and it possessed internal waves, particularly in the lower regions of the flow. The flow history at the measurement height nearest to the bed (i.e., at $z=23 \mathrm{~mm}$ ) was characterized by a steady phase followed by a waning phase (Fig. 19), with superimposed velocity fluctuations on a scale of $\sim 5 \mathrm{~s}$. The amplitude and frequency of these low-frequency fluctuations, the height at which they occurred and the scarcity of highfrequency fluctuations, closely resemble the velocity time series typical of the upper transitional plug flow in the present study. Felix et al. (2005) suggested that the velocity fluctuations were associated with internal waves generated at a shear layer above the level of maximum velocity. The present study suggests that they more likely may have been associated with a near-bed internal shear layer within an upper transitional plug flow, especially since the waves appear to become less pronounced closer to the velocity maximum at $z=41$ mm (Figure 2 of Felix et al. 2005). Felix et al. (2005) contended that the influence of bed shear did not extend as far upward as $z=23 \mathrm{~mm}$, although no near-bed data were presented to support this. Although the flow-history curve passes through the lower and upper transitional plug flow phases several times, it mostly resides within the quasi-laminar flow phase (Figure 19; $\mathrm{Re}=2000-10,000$ with the height of the velocity maximum chosen as approximate length scale). This phase-space position appears in contrast with the transitional flow dynamics suggested by the velocity time series. However, the stability regimes for density flows may not coincide exactly with those of open-channel flows, because of differences in flow structure and turbulence generation, particularly at the upper flow boundary. For the density flow to be classified as an upper transitional plug flow, the boundary with quasi-laminar flow has to shift to higher concentrations, effectively meaning that turbulent forces need to increase with respect to cohesive forces. This is a reasonable assumption, because turbulence near the top of density flows (generated as "billows" through Kelvin-Helmholtz instability) is stronger than near the free surface of hydrodynamically equivalent openchannel flows. Finally, it is worthwhile mentioning that the non depositional nature of the flow studied by Felix et al. (2005) is predicted well by the path of the flow history curve in the phase diagram (Fig. 19).

Scarlatos and Wilder (1990) conducted lock-exchange experiments with subaqueous hyperconcentrated flows transporting kaolinite and natural mud. The natural mud was composed of organic matter (43\%), silt (42\%), and sand (15\%). At initial concentrations of 8\% and 16\%, both sediments behaved in a similar manner (Fig. 19), which inspires confidence that kaolinite is a reasonable analogue for natural fine-grained, 
cohesive sediment. All flows were laminar in a layer 0.01-0.05 m thick above the bed, where the effect of shear at the upper boundary was negligible, and they were also depositional. This agrees well with their position in the flow phase diagram (Fig. 19) and with typical Reynolds numbers well within the quasilaminar flow phase $(100<\operatorname{Re}<4000)$. Huang and García (1998) used kaolinite to investigate the runout distance of subaerial mudflows in a laboratory channel. From the changing spreading rate of a flow laden with $13.05 \%$ clay (Fig. 19) and the presence of an internal shear layer at $z=0.02-0.04 \mathrm{~m}$, it can be deduced that the flow was laminar along its entire flow path with $400<\mathrm{Re}<3000$. This is consistent with the assumption of Huang and García (1998).

Wan (1982) presented velocities and sediment concentrations of hyperconcentrated flows at the confluence of the Yellow River and the Wei River in China. The rivers were about $6 \mathrm{~m}$ deep and carried mud with a clay component dominated by illite. Typical flow velocities were between $1 \mathrm{~m} \mathrm{~s}^{-1}$ and $2 \mathrm{~m} \mathrm{~s}^{-1}$, and concentrations decreased from $\sim 20 \%$ near the river bed to $\sim 2 \%$ near the water surface. Mean concentrations in the center of the rivers were $12.1 \%$ and $8.7 \%$ just downstream of the confluence (Fig. 19). If the kaolinite flow phase diagram is used as guideline, these flow conditions suggest that the flows recorded by Wan (1982) were laminar near the bed, transitional at mid-depth, and turbulent near their top, However, since illite has a higher yield stress than kaolinite and the flows contained large amounts of noncohesive silt-size sediment as well, these complications inhibit further comparisons at present with the physical models for transitional flow proposed herein.

Lastly, it is worthy of note that Schieber et al. (2007) have recently reported on the production of clay floccules in low-velocity laboratory water flows transporting mud- and silt-grade sediment. These mud floccules were found to generate small mud ripples that were argued to be of great potential importance in the formations of mudrocks, although such ripples were formed only at low flow velocities. Under such lowvelocity, depositional conditions, with typical Froude and Reynolds numbers of, respectively, 0.3-0.4 and $10,000-20,000$, the production of a reduced-velocity zone near the bed, such as that quantified in the transitional flows studied herein, may provide a region in which such floccules can form. This would thus provide an increased period of time for formation of such clay floccules under conditions in which the mean flow velocity of the upper flow may be too high to suggest that clay floccules and floccule ripples could exist. The formation and nature of transitional flows may therefore be critical in allowing the formation of larger clay particles, and in influencing the formation of many mudrocks. 


\section{CONCLUSIONS}

The results of flume experiments with kaolinite-laden open-channel flows reveal predictable changes in the dynamic structure of flow with increasing suspended-sediment concentration. At flow velocities typical of many natural environments, flows pass through five phases as clay concentration increases: (1) turbulent flow; (2) turbulence-enhanced transitional flow; (3) lower transitional plug flow; (4) upper transitional plug flow; and (5) quasi-laminar plug flow. The dynamic structure of these flow types is controlled by turbulent forces, related to internal shear stresses and shear stress at the flow boundaries, and cohesive forces, associated with increased viscous stress when clay particles form turbulence-modulating gels. Turbulence is pervasive in the turbulent flows, with the amount of clay particles being insufficient to affect flow conditions. The turbulent clay flows thus behave in a manner identical to that of flows free of clay. Flows in the turbulence-enhanced transitional flows are strongly turbulent throughout the flow depth, with turbulence enhancement resulting from development of an internal shear layer close to the base of the flow. This phase may be similar to that envisaged in past studies of drag reduction caused by suspended clay, which has been shown to cause an increase in the thickness of the viscous sublayer. Cohesive forces start to influence the flow structure in lower transitional plug flows, where electrostatic bonding between clay particles initiates a plug-flow region without, or with a very low, vertical gradient in streamwise velocity and a lack of turbulence. This plug-flow region expands downwards as clay concentration increases. At the same time, turbulence intensity continues to increase near the base of the flows, where an internal shear layer produces additional turbulent energy. The turbulent flow structures produced within this shear layer dissipate quickly as they advect upwards into the outer flow. Viscous stresses become dominant in upper transitional plug flows, as evidenced by a general decrease in turbulence intensity and a further expansion of the plug flow. The internal shear layer persists, but it quickly loses its turbulent character with increasing clay concentration, eventually leading to formation of a pervasive gel in quasi-laminar plug flows. In this phase, shear ceases to produce sufficient turbulence to break up the bonds between clay particles, and a laminar

plug flow riding on a thin layer with a high velocity gradient is generated. Slow flows in the transitional and quasi-laminar plug flows are depositional, because they are oversaturated with sediment. 
Stability analysis of these clay flow phases reveals that many natural clay-laden flows should exhibit a transitional flow behavior, even if the fundamental, simplified nature of the laboratory experiments is taken into account. The different processes of turbulence modulation identified herein are expected to have major implications for the dynamics and distribution of clay-rich flows and their depositional products, with transitional flows probably occurring in a far wider range of aquatic environments than previously thought.

\section{ACKNOWLEDGMENTS}

We are very grateful to the UK Natural Environment Research Council for a grant (NE/C514823/1) that enabled this research to be undertaken at the Sorby Environmental Fluid Dynamics Laboratory, whilst JHB and JLB were at Leeds. Mark Franklin and Phil Kellman are thanked for their support in the laboratory. We also acknowledge the valuable comments by JSR Editor Paul McCarthy, Associate Editor Sue Marriott, Technical Editor John Southard, and two anonymous reviewers. 


\section{REFERENCES}

BAAS, J.H., AND BEST, J.L., 2002, Turbulence modulation in clay-rich sediment-laden flows and some implications for sediment deposition: Journal of Sedimentary Research, v. 72, p. 336-340.

BAAS, J.H., AND BEST, J.L., 2008, The dynamics of turbulent, transitional and laminar clay-laden flow over a fixed current ripple: Sedimentology, v. 55, p. 635-666.

BAGNOLD, R.A., 1954, Experiments on a gravity-free dispersion of large, solid spheres in a Newtonian fluid model shear: Royal Society of London, Proceedings, v. A225, p. 49-63.

BEST, J.L., 1992, Sedimentology and event timing of a catastrophic volcaniclastic mass flow, Volcan Hudson, Southern Chile: Bulletin of Volcanology, v. 54, p. 299-318.

BEST, J.L., 1998, The influence of particle rotation on wake stability at particle Reynolds numbers, $\operatorname{Re}_{\mathrm{p}}<300$ - implications for turbulence modulation in two-phase flows: International Journal of Multiphase Flow, v. 24, p. 693-720.

BEST, J.L., AND LEEDER, M.R., 1993, Drag reduction in turbulent muddy seawater flows and some sedimentary consequences: Sedimentology, v. 40, p. 1129-1137.

BEst, J.L., BENNETT, S., BRIDGE, J., and LEEDER, M., 1997, Turbulence modulation and particle velocities over flat sand beds at low transport rates: Journal of Hydraulic Engineering, v. 123, p. 1118-1129.

BEST, J.L., KIRKBRIDE, A.D., and PEAKALL, J., 2001, Mean flow and turbulence structure of sedimentladen gravity currents: new insights using ultrasonic Doppler velocity profiling, in McCaffrey, W.D., Kneller, B.C, and Peakall, J., eds., Particulate Gravity Currents: International Association of Sedimentologists, Special Publication 31, p. 159-172.

COLES, D., 1956, The law of the wake in the turbulent boundary layer: Journal of Fluid Mechanics, v. 1, p. 191-226.

Coussot, P., 1995, Structural similarity and transition from Newtonian to non-Newtonian behavior for claywater suspensions: Physical Review Letters, v. 74, p. 3971-3974.

Coussot, P., 1997, Mudflow Rheology and Dynamics: Delft Hydraulics, International Association for Hydraulic Research, Monograph, 270 p.

Coussot, P., AND MeunieR, M., 1996, Recognition, classification and mechanical description of debris flows: Earth-Science Reviews, v. 40, p. 209-227. 
ELGOBASHI, S., 1994, On predicting particle-laden turbulent flows: Applied Scientific Research, v. 52, p. 309-329.

FeliX, M., StURTON, S., AND PeAKall, J., 2005, Combined measurements of velocity and concentration in experimental turbidity currents: Sedimentary Geology, v. 179, p. 31-47.

GORE, R.A., AND CROWE, C.T., 1989, Effect of particle size on modulating turbulent intensity: International Journal of Multiphase Flow, v. 15, p. 279-285.

HuANG, X., AND GarCíA, M.H., 1998, A Herschel-Bulkley model for mud flow down a slope: Journal of Fluid Mechanics, v. 374, p. 305-333.

KRANENBURG, C., 1994, The fractal structure of cohesive sediment aggregates: Estuarine, Coastal and Shelf Science, v. 39, p. 451-460.

Krone, R.B., 1963, A Study of Rheological Properties of Estuarine Sediments: Technical Report 638. Berkeley: Hydraulic Engineering Laboratory and Sanitary Engineering Laboratory, University of California.

LAVIGNE, F., AND THOURET, J.C., 2000, Les lahars : dépôts, origines et dynamique: Societé Geologique de France, Bulletin, v. 171, p. 545-557.

LI, M.Z., AND GUST, G., 2000, Boundary layer dynamics and drag reduction in flows of high cohesive sediment suspensions: Sedimentology, v. 47, p. 71-86.

LOWE, D.R., 1982, Sediment gravity flows: II. Depositional models with special reference to the deposits of high-density turbidity currents: Journal of Sedimentary Petrology, v. 52, p. 279-297.

LOWE, D.R., AND GuY, M., 2000, Slurry-flow deposits in the Britannia Formation (Lower Cretaceous), North Sea: A new perspective on the turbidity current and debris flow problem: Sedimentology, v. 47, p. $31-70$

MAJOR, J.J., JANDA, R.J., AND DAAG, A.S., 1996, Watershed disturbance and lahars on the east side of Mount Pinatubo during the mid-June 1991 eruptions, in Newhall, C.G., and Punongbayan, R.S., eds., Fire and Mud: Eruptions and Lahars Of Mount Pinatubo, Philippines: Vancouver, U.S. Geological Survey, p. 895-919.

MERCKELBACH, L.M., AND KRANENBURG, C., 2004, Equations for effective stress and permeability of soft mud-sand mixtures: Géotechnique, v. 54, p. 235-243. 
MidDleton, G.V., 1967, Experiments on density and turbidity currents. III. Deposition of sediment: Canadian Journal of Earth Sciences, v. 4, p. 475-505.

Migniot, C., 1968, Etude des propriétés physiques de différents sediments très fins et de leur comportement sous des actions hydrodynamiques: La Houille Blanche, v. 7, 591-620.

Migniot, C., 1989, Tassement et rhéologie des vases: La Houille Blanche, v. 12, p. 95-111.

Mohrig, D., ElVERhøI, A., AND PARKer, G., 1999, Experiments on the relative mobility of muddy subaqueous and subaerial debris flows, and their capacity to remobilize antecedent deposits: Marine Geology, v. 154, p. 117-129.

MuldER, T., AND ALEXANDER, J., 2001, The physical character of subaqueous sedimentary density flows and their deposits: Sedimentology, v. 48, p. 269-299.

NEZU, I., AND NAKAGAWA, H., 1993, Turbulence in Open-Channel Flows: Delft Hydraulics, International Association for Hydraulic Research, Monograph, 286 pp.

PARKer, G., FuKushimA, Y., AND PANTIN, H.M., 1986, Self accelerating turbidity currents: Journal of Fluid Mechanics, v. 171, p. 145-181.

PIERSON, T.C., AND ScotT, K.M., 1985, Downstream dilution of a lahar: Transition from debris flow to hyperconcentrated streamflow: Water Resources Research, v. 21, p. 1511-1524.

SCARlATOS, P.D., AND WILDER, B.J., 1990, Experimental investigations of density-driven hyperconcentrated flows, in Hydraulics/Hydrology of Arid Lands: Proceedings of the International Symposium, San Diego, California, July $30^{\text {th }}-$ Aug $2^{\text {nd }}$, p. 633-638.

SCHIEBER, J., SOUTHARD, J., AND THAISEN, K., 2007, Accretion of mudstone beds from migrating floccule ripples: Science, v. 318, p. 1760-1763.

TAKEDA, Y., 1991, Development of an ultrasound velocity profile monitor: Nuclear Engineering and Design, v. 126, p. 277-284.

TrAYKOVSKI, P., GEYER, W.R., IRISH, J.D., AND LYNCH, J.F., 2000, The role of wave-induced densitydriven fluid mud flows for cross-shelf transport on the Eel River continental shelf: Continental Shelf Research, v. 20, p. 2113-2140.

VAn Kessel, T., AND KRANENBURG, C., 1996, Gravity currents of fluid mud on sloping bed: Journal of Hydraulic Engineering, v. 122, p. 710-718. 
VAN OlPhen, H., 1977, An Introduction to Clay Colloid Chemistry, 2nd Edition: London, John Wiley \& Sons, $318 \mathrm{p}$.

VAN RiJn, L.C., 1990, Principles of Fluid Flow and Surface Waves in Rivers, Estuaries, Seas and Oceans: Amsterdam, Aqua Publications, 335 p.

WAN, Z., 1982, Bed material movement in hyperconcentrated flow: Technical University of Denmark, Institute of Hydrodynamics and Hydraulic Engineering, Lyngby, Series Paper 31, 79 p.

WAN, Z, AND WANG, Z.Y., 1994, Hyperconcentrated flow: Rotterdam. The Netherlands, A.A. Balkema, 320

p.

WANG, X., WANG, Z.Y., YU, M., AND LI, D., 2001, Velocity profile of sediment suspensions and comparison of log-law and wake-law: Journal of Hydraulic Research, v. 39, p. 211-217.

WANG, Z.Y., AND LARSEN, P., 1994, Turbulence structure of flows of water and clay suspensions with bedload: Journal of Hydraulic Engineering, v. 120, p. 577-600.

WANG, Z.Y., LARSEN, P., NESTMANN, F., AND DitTRICH, A., 1998, Resistance and drag reduction of flows of clay suspensions: Journal of Hydraulic Engineering, v. 124, p. 41-49.

WANG, Z., AND Plate, E.J., 1996, A preliminary study on the turbulence structure of flows on nonNewtonian fluid: Journal of Hydraulic Research, v. 34, p. 345-361.

WinterWERP, J.C., AND VAN KeSTEREN, W.G.M., 2004, Introduction to the Physics of Cohesive Sediment in the Marine Environment: Oxford, United Kingdom, Elsevier, Developments in Sedimentology 56, 559 p. 


\section{FIGURE CAPTIONS}

Table 1. - Experimental parameters for the experiments described in the present paper.

Fig. 1. - Schematic diagram of the experimental setup. UDVP = ultrasonic Doppler velocity profilers.

Fig. 2. - Vertical profile of time-averaged downstream velocity, $\bar{U}$, for an upper transitional plug flow (run 5-20; black dots). Regression analysis show that the wake function of Coles (1956) (continuous line) yields a better fit than the logarithmic law of the wall (dashed line).

Fig. 3. - Representative vertical profiles of volumetric suspended sediment concentration. $c=$ suspended sediment concentration at height $z ; h=$ flow depth.

Fig. 4. - Representative vertical profiles of A) dimensionless downstream velocity, $\bar{U} / \bar{U}_{\max }$, B) root-meansquare of downstream velocity, RMS $\left(u^{\prime}\right)$, and $\mathbf{C}$ ) dimensionless turbulence intensity, RMS $\left(u^{\prime}\right)_{0}$, for a flow velocity range between $0.129 \mathrm{~m} \mathrm{~s}^{-1}$ and $0.172 \mathrm{~m} \mathrm{~s}^{-1}$ and suspended-sediment concentrations increasing from 0.04\% to 5.33\%. Abbreviations in legend denote flow types discussed in the text and summarized in Figure 15A.

Fig. 5. - As Figure 4, but for a velocity range between $0.405 \mathrm{~m} \mathrm{~s}^{-1}$ and $0.451 \mathrm{~m} \mathrm{~s}^{-1}$ and suspended-sediment concentrations increasing from $0.15 \%$ to $14.47 \%$.

Fig. 6. - As Figure 4, but for a velocity range between $0.879 \mathrm{~m} \mathrm{~s}^{-1}$ and $0.940 \mathrm{~m} \mathrm{~s}^{-1}$ and suspended-sediment concentrations increasing from $0.85 \%$ to $15.34 \%$.

Fig. 7. - As Figure 4, but for a velocity ranging between $1.245 \mathrm{~m} \mathrm{~s}^{-1}$ and $1.433 \mathrm{~m} \mathrm{~s}^{-1}$ and suspended-sediment concentrations increasing from $7.45 \%$ to $16.67 \%$. 
Fig. 8. - Normalized vertical profiles of dimensionless downstream flow velocity, $\bar{U}$, (left) and turbulence intensity, RMS $\left(u^{\prime}\right)_{0}$, (right) for A) turbulent flows, B) turbulence-enhanced transitional flows, C) lower transitional plug flows, D) upper transitional plug flows, and E) quasi-laminar plug flows. Horizontal lines represent the range of data at the given height; open circles denote mean values; and short vertical lines represent standard deviations. Best-fit curves for turbulent flows in Part A are also shown for comparison in Parts B-E. Best-fit equations are based on mean velocities and mean turbulence intensities. $R^{2}=$ coefficient of determination; $z$ = height in flow; $h$ = flow depth.

Fig. 9. - Schematic models for the five different clay flow types defined in this paper. The graphs to the left of the models denote characteristic velocity time series at various heights in the flows. The graphs to the right of the models represent characteristic vertical profiles of dimensionless downstream velocity $\left(\bar{U} / \bar{U}_{\max }\right)$, root-mean-square of downstream velocity (RMS $\left.\left(u^{\prime}\right)\right)$ and dimensionless turbulence intensity $\left(\operatorname{RMS}\left(u^{\prime}\right)_{0}\right)$.

Fig. 10. - Characteristic time series of downstream velocity, $u$, at different dimensionless heights, $z / h$, in A) turbulent flows and B) turbulence-enhanced transitional flows, for runs 5-3 $(C=0.40 \%)$ and 5-9 $(C=4.82 \%)$ respectively. Arrows denote sub-second-scale velocity fluctuations superimposed onto the rising and falling limbs of second-scale fluctuations in the turbulence-enhanced transitional flow. $t=$ time.

Fig. 11. - Characteristic time series of downstream velocity, $u$, at different dimensionless heights, $z / h$, in lower transitional plug flows. A) run 2-10, $C=5.36 \%$, B) run $4-17, C=10.69 \%, \mathbf{C}$ ) run $7-20, C=13.11 \%$. Velocities in Run 7-20 were recorded at a higher frequency than in Runs 2-10 and 4-17 (Table 1). Short gaps in the time series of Run 4-17 correspond to short periods in which the UDVP was unable to record velocity data. Arrows denote short periods of low velocity, which are inferred to have shed off the top of KelvinHelmholtz instabilities in the near-bed shear layer of the lower transitional plug flows. $t=$ time.

Fig. 12. - Concentration-induced changes in velocity time series at $z / h=0.03$ in flows with a depth-averaged velocity of $\sim 1.4-1.6 \mathrm{~m} \mathrm{~s}^{-1}$. $C=$ depth-averaged clay concentration; $t=$ time; $u=$ downstream velocity. 
Fig. 13. - Schematic model for clay-laden flow of transient turbulent behavior moving over a flat, fixed boundary (modified after Baas and Best 2002). Flow is from left to right. The flow sketch depicts streamlines. Typical vertical profiles of time-averaged horizontal velocity, $u$, and its root-mean-square value, RMS $\left(u^{\prime}\right)$ are shown to the right of the model. The insets below the model denote characteristic time series of horizontal velocity at three different heights in the flow. Note that the transitional flow has an internal shear layer that separates a lower region of high velocity gradient from an upper layer of reduced shear. Turbulence is strongest in the shear layer, along which Kelvin-Helmholtz instabilities are developed. From the shear layer, packages of low-velocity fluid are ejected into the outer flow region. Downward-directed, high-velocity events produce asymmetric downstream-velocity traces near the base of the flow. $z=$ height in flow; $t=$ time; $x$ = horizontal distance.

Fig. 14. - Characteristic time series of downstream velocity, $u$, at different dimensionless heights, $z / h$, in: A) upper transitional plug flows (run 6-20; $C=13.09 \%$ ) and $\mathbf{B}$ ) quasi-laminar plug flows (run 6-24; $C=$ 15.34\%). $t=$ time.

Fig. 15. - A) Phase diagram for kaolinite flows moving over a flat, smooth, fixed boundary. The phase space for turbulent, transitional, and laminar flows is shown as a function of depth-averaged flow velocity, $\overline{\bar{U}}$, and depth-averaged clay concentration, $C$. Note the depositional phase, in which the flows fail to support clay particles. B) Inferred continuation of phase boundaries (dashed lines) at very low velocities and clay concentrations.

Fig. 16. - Near-bed RMS $\left(u^{\prime}\right)$ plotted against mean clay concentration, $C$, in narrow velocity ranges between $0.94 \mathrm{~m} \mathrm{~s}^{-1}$ and $1.05 \mathrm{~m} \mathrm{~s}^{-1}$ (Runs 7-1 to 7-24) and between $0.40 \mathrm{~m} \mathrm{~s}^{-1}$ and $0.45 \mathrm{~m} \mathrm{~s}^{-1}$ (Runs 3-1 to 3-22), showing a gradual increase in turbulence intensity (turbulence-enhanced transitional flows and lower transitional plug flows) followed by a rapid decrease in turbulence intensity (upper transitional plug flows). 
Fig. 17. - Phase diagram for kaolinite flows moving over a flat, smooth, fixed boundary, plotted using the Froude number, Fr, and flow Reynolds number, Re. Note that this diagram is valid only for flow depths between $0.13 \mathrm{~m}$ and $0.16 \mathrm{~m}$.

Fig. 18. - Fr-Re phase diagram for montmorillonite flows moving over a smooth boundary, based on the experimental flows with $h>0.03 \mathrm{~m}$ reported by Wang and Plate (1996). Also shown are the phase boundaries between turbulent, transitional, and laminar flow types from the present study.

Fig. 19. - Clay flow phase diagram superimposed with data from selected literature sources. See Figure 15A for explanation of abbreviations. 


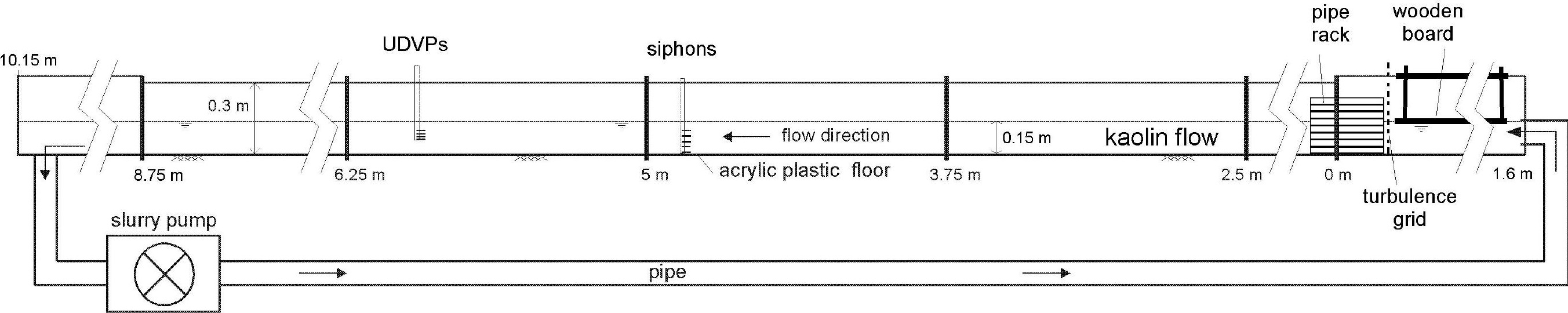




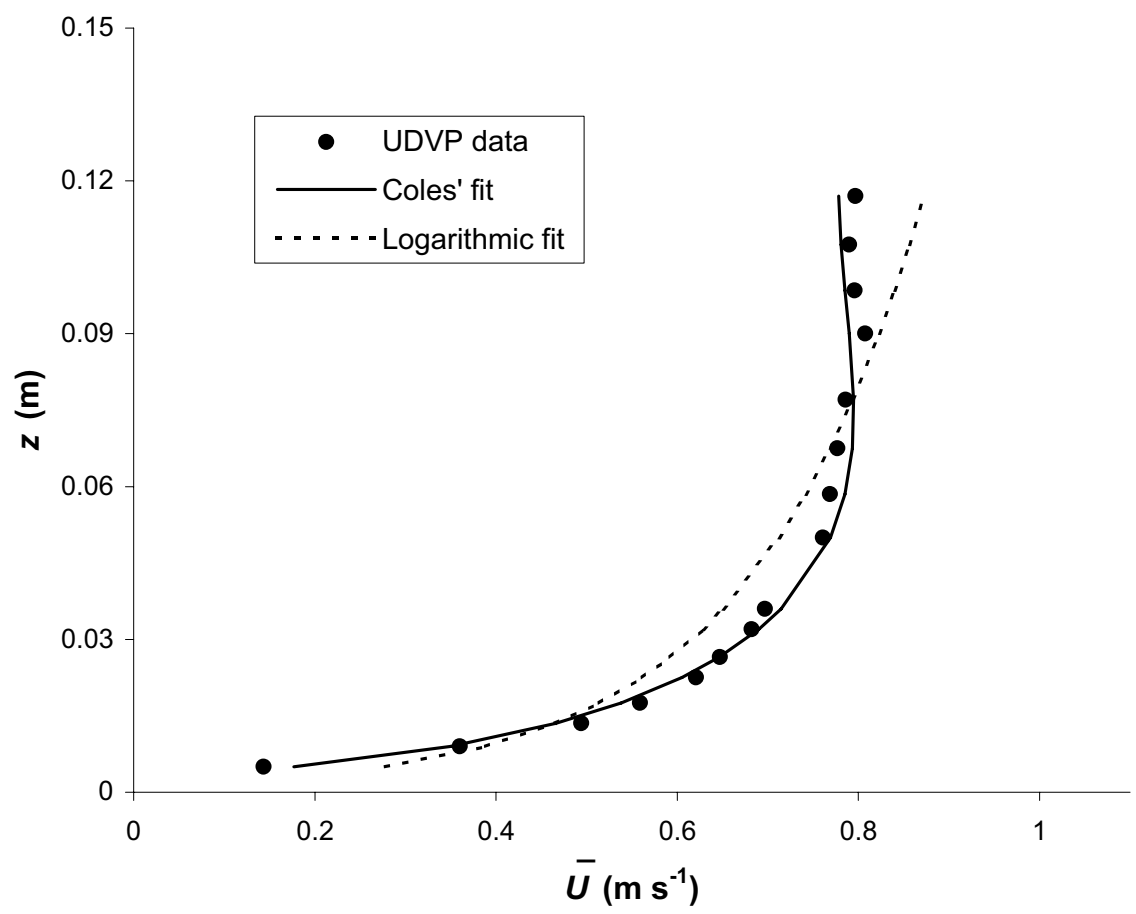




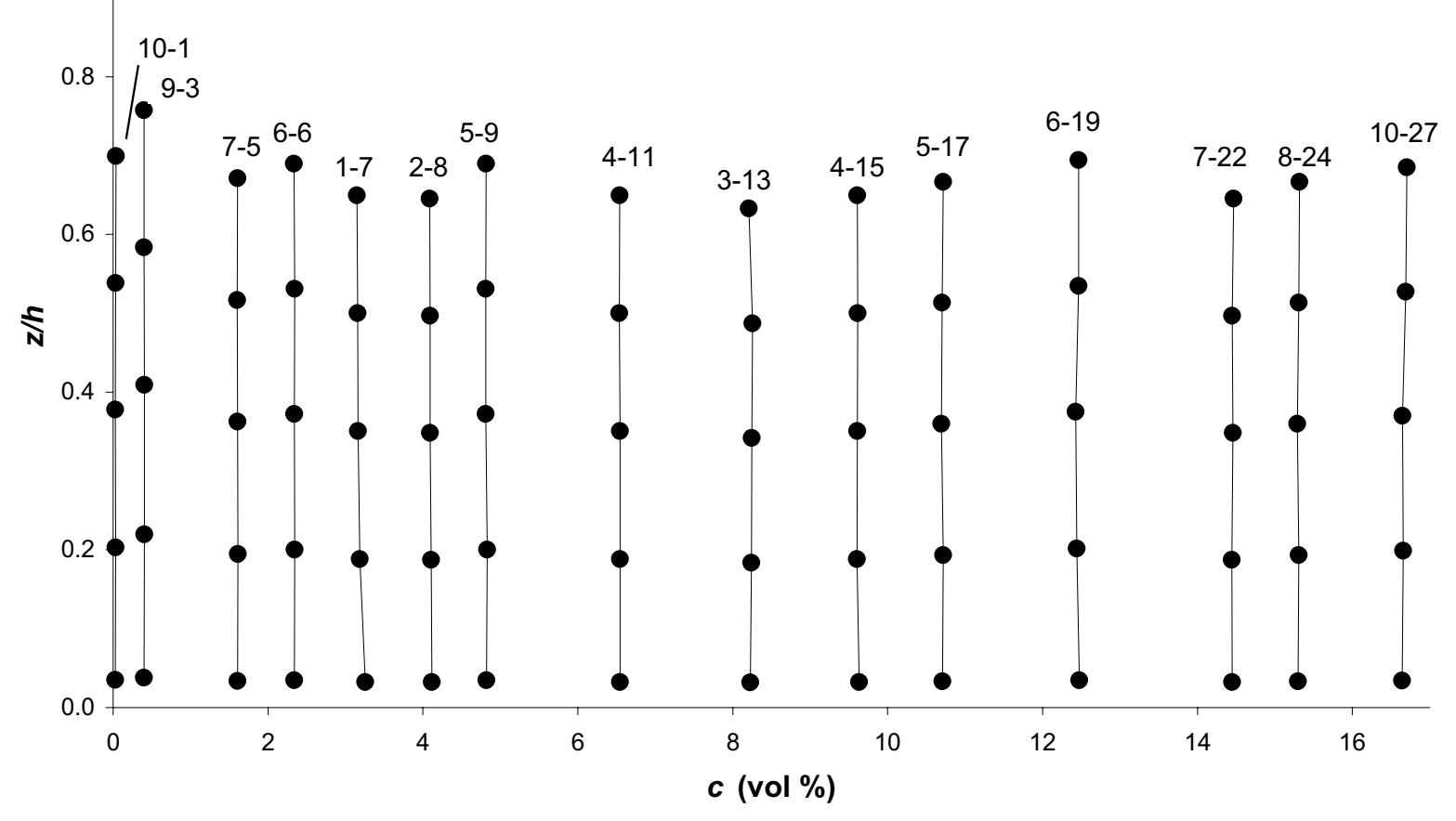



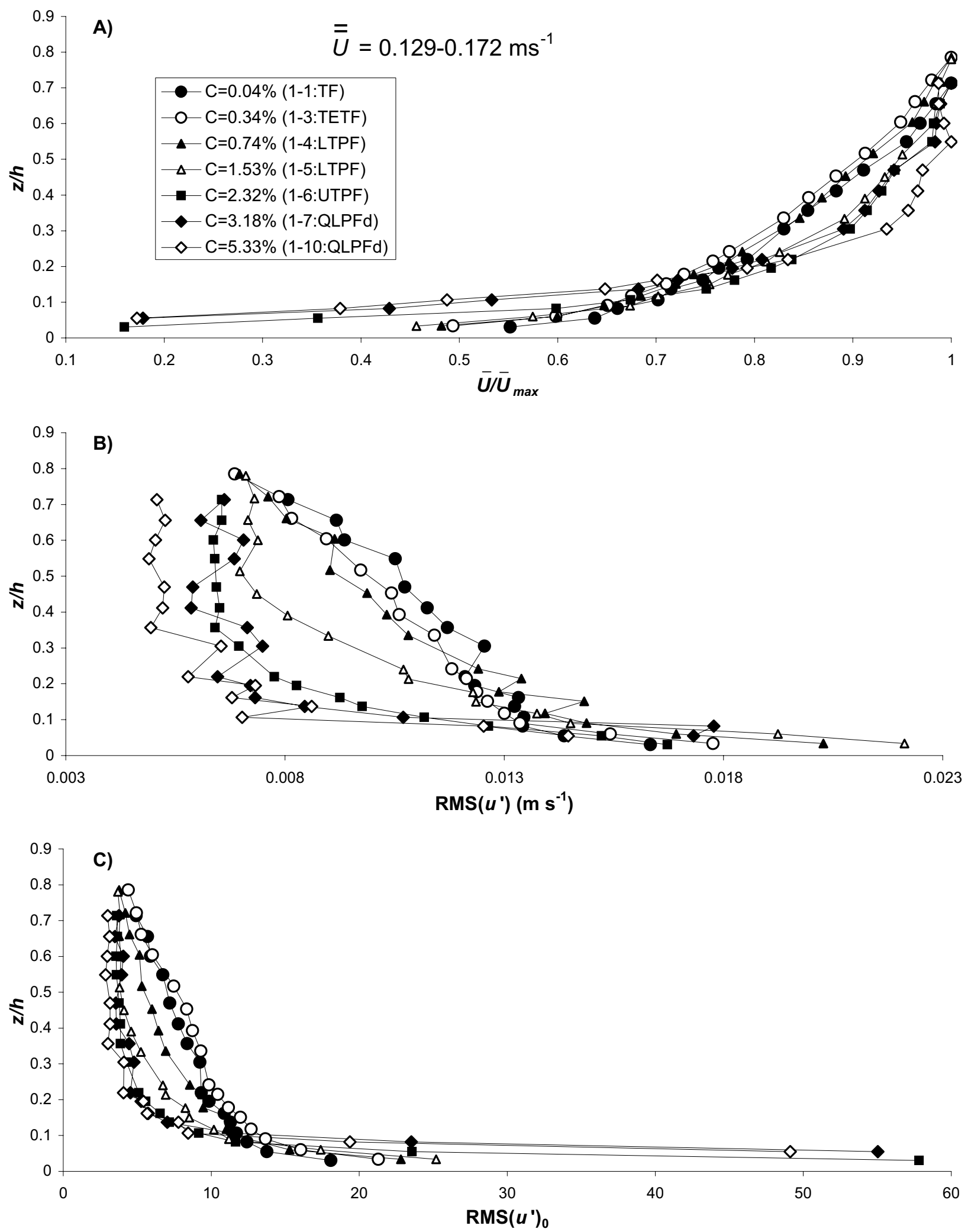

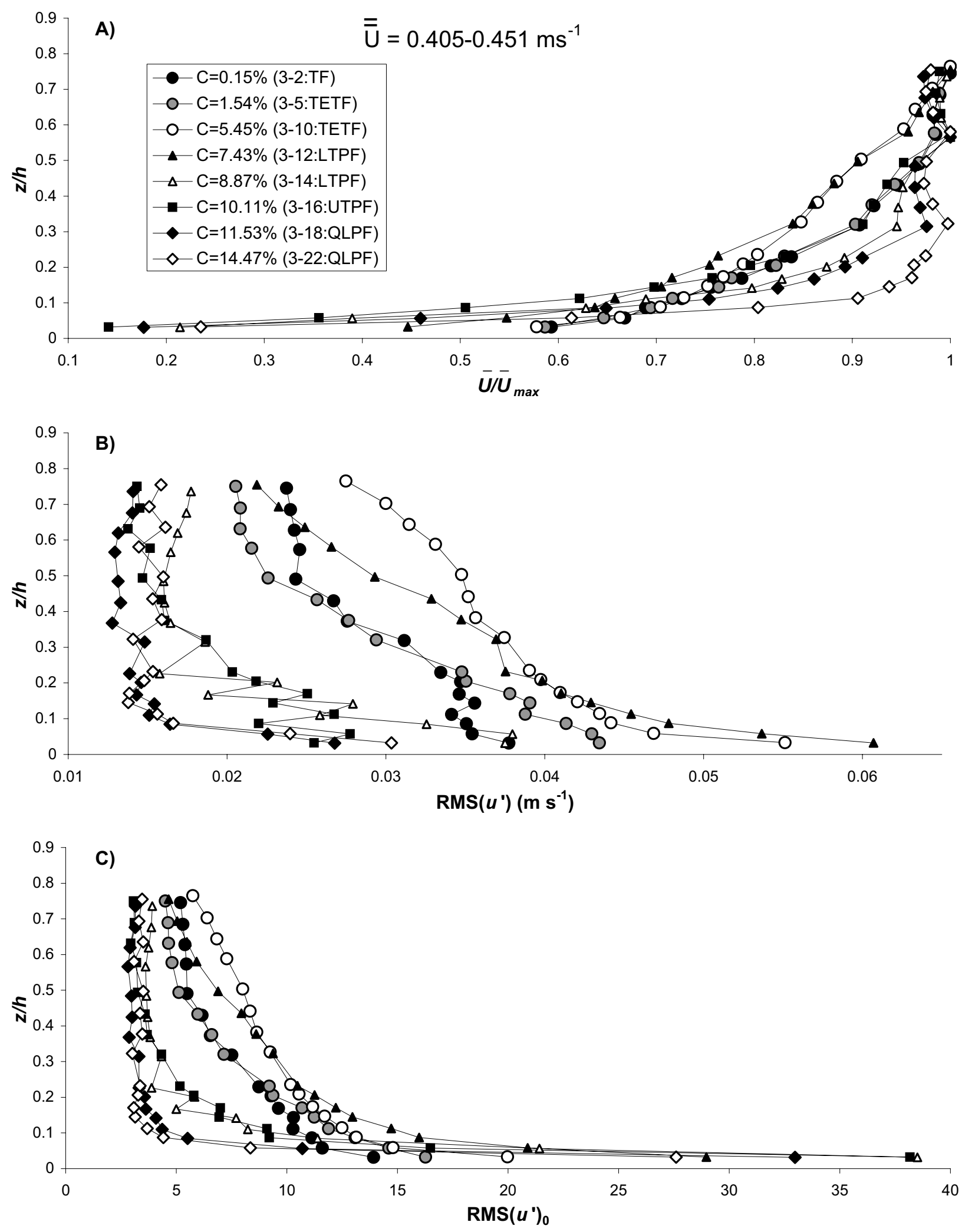

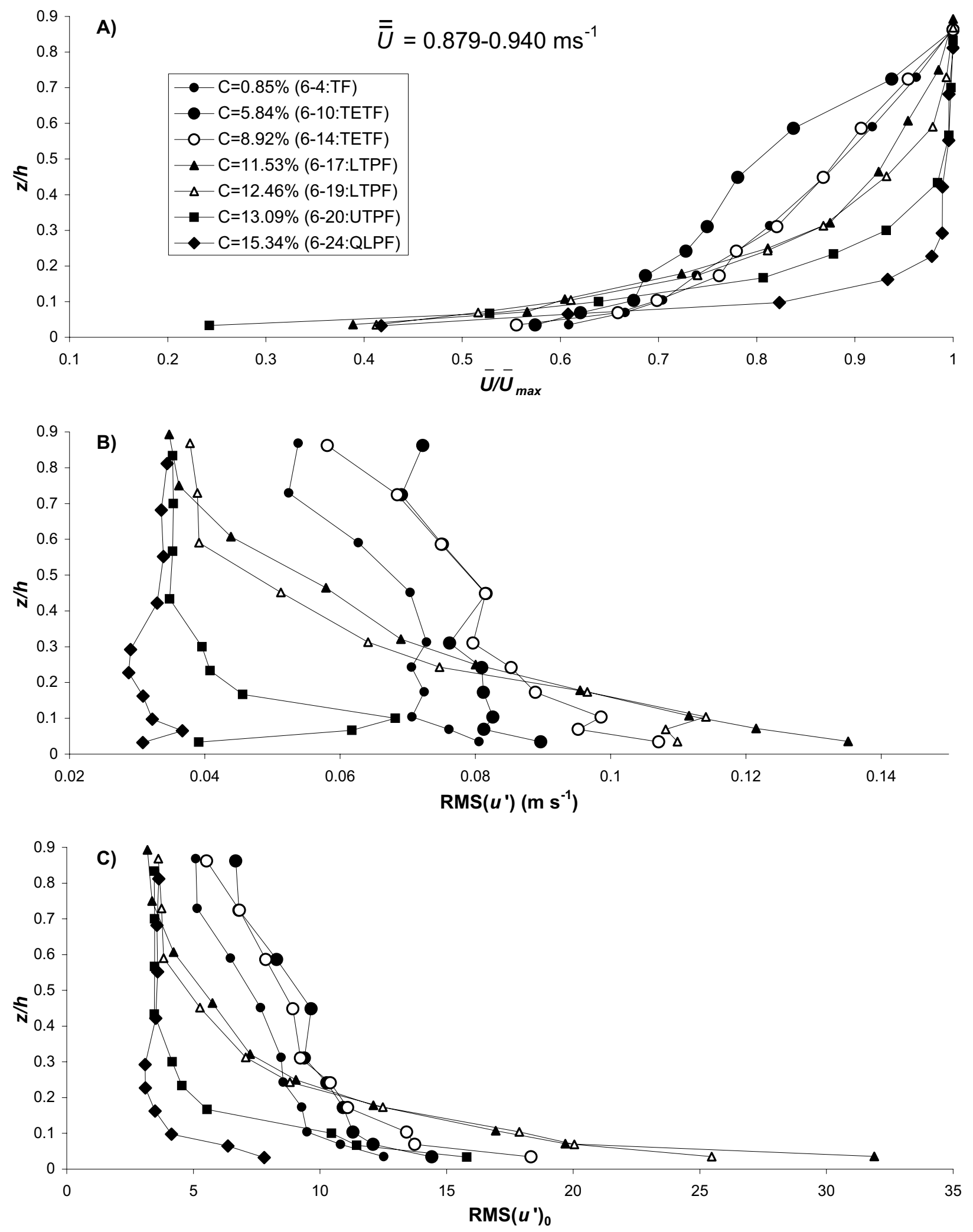

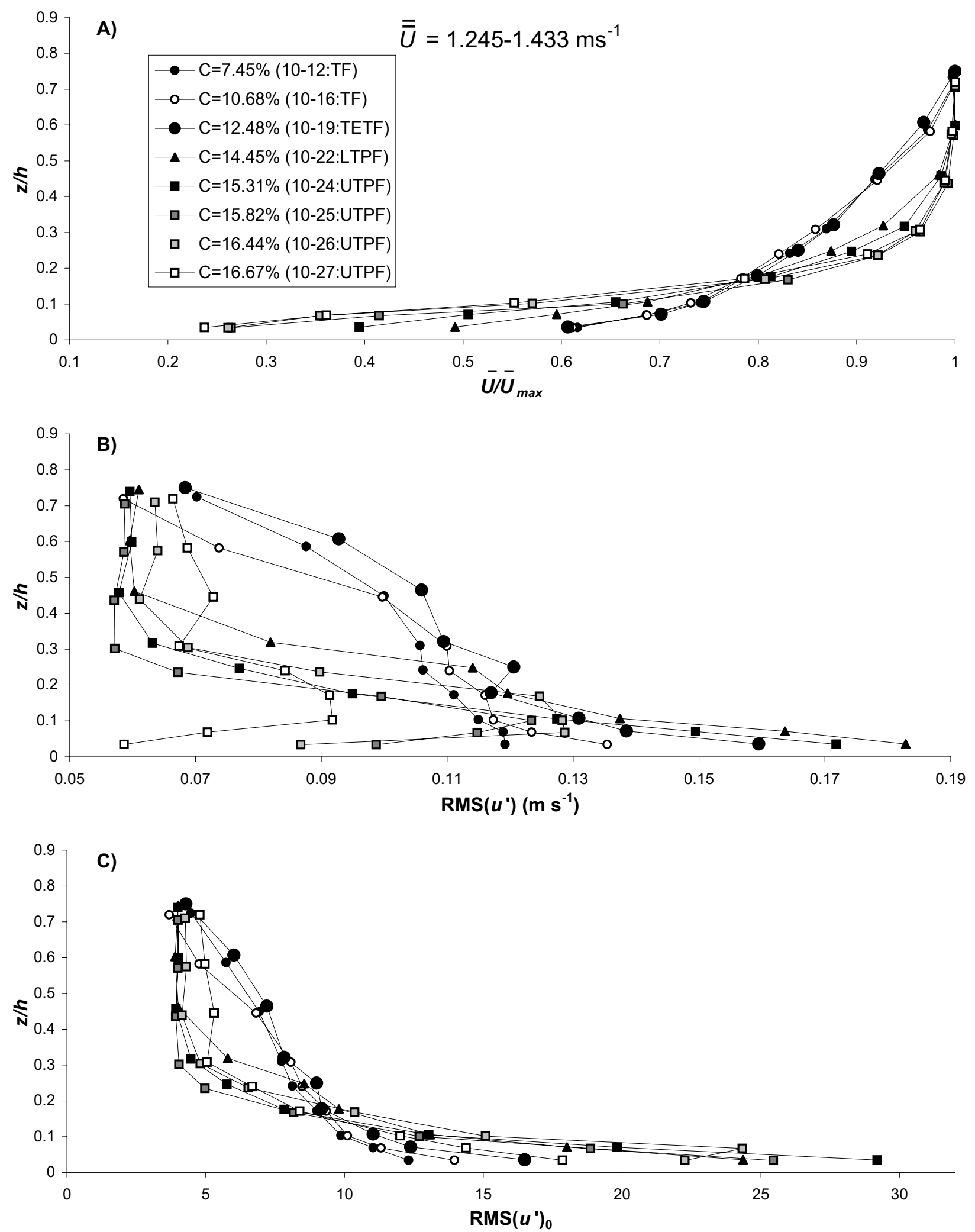

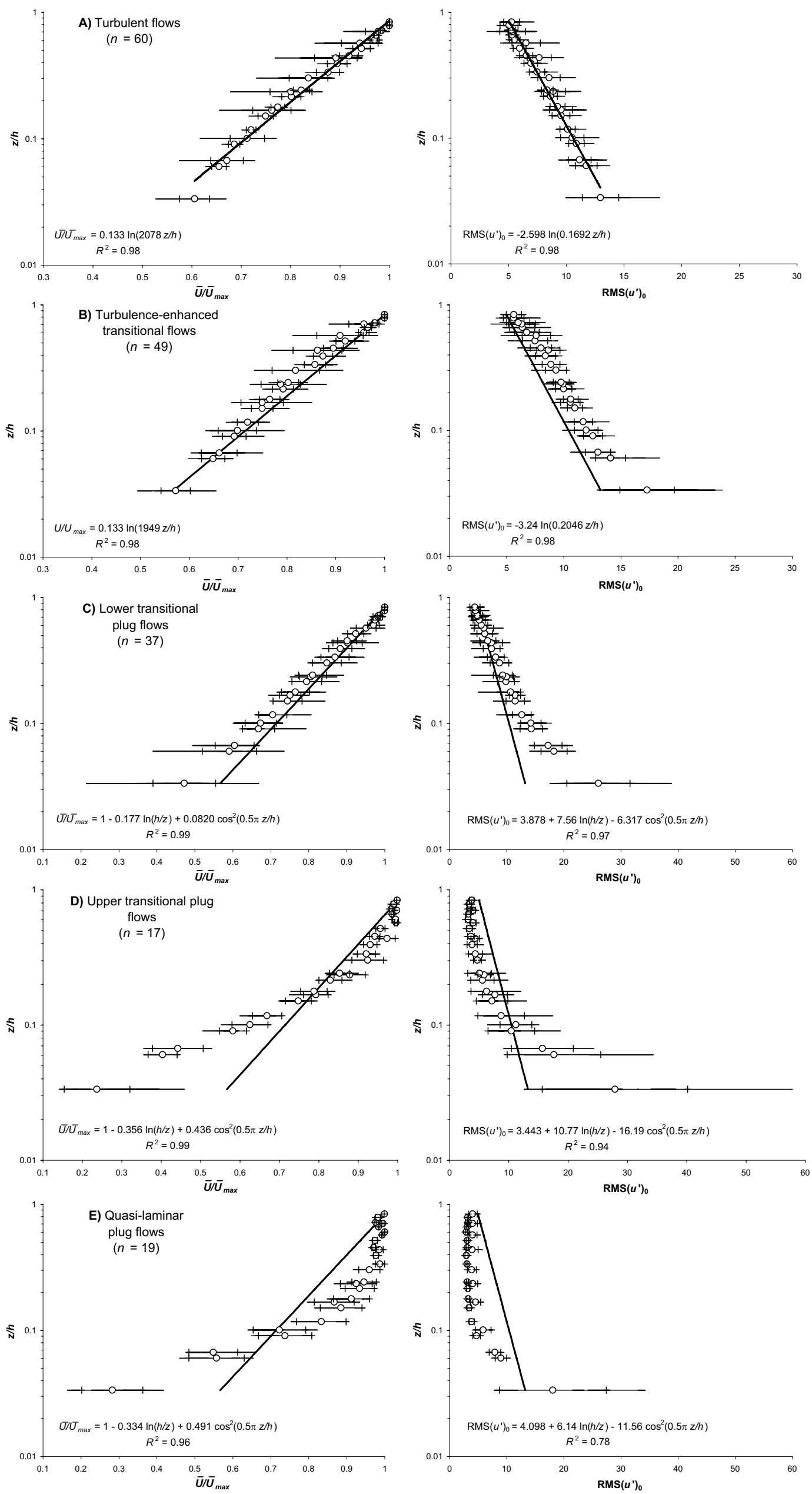
time-series

(a) Turbulent flow

$\bar{U} / U_{\max } \quad \operatorname{RMS}\left(u^{\prime}\right) \quad \operatorname{RMS}\left(u^{\prime}\right)_{0}$

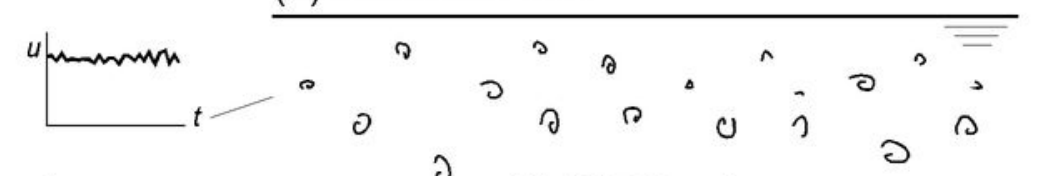

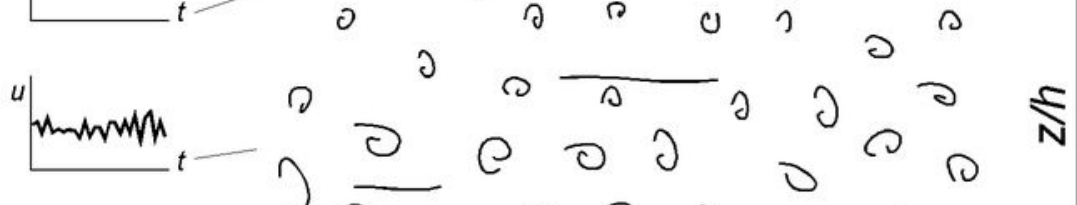

a 0 e 0 o 0 - (c)

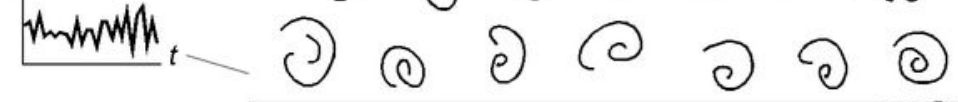

(b) Turbulence-enhanced transitional flow
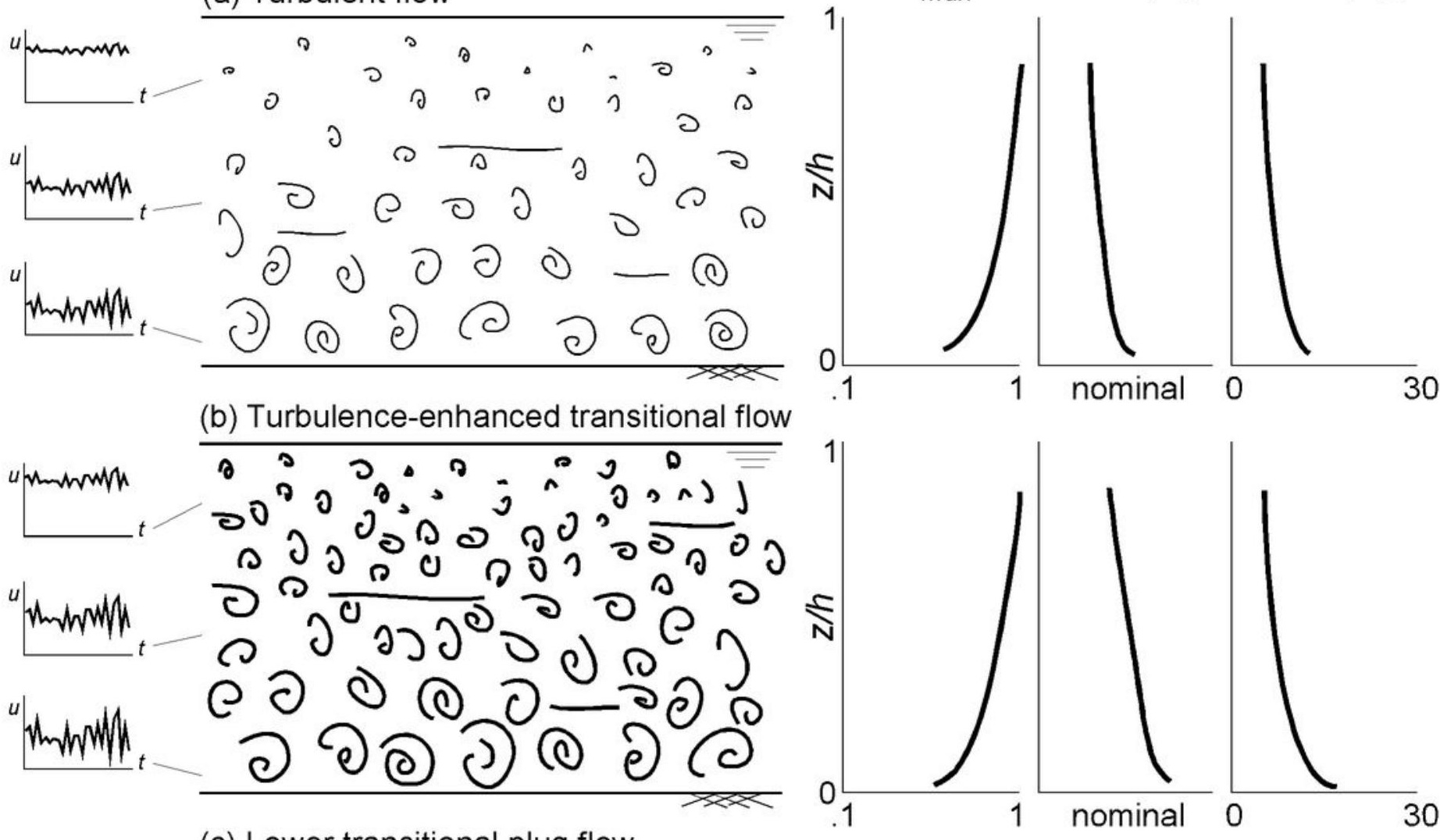

(c) Lower transitional plug flow

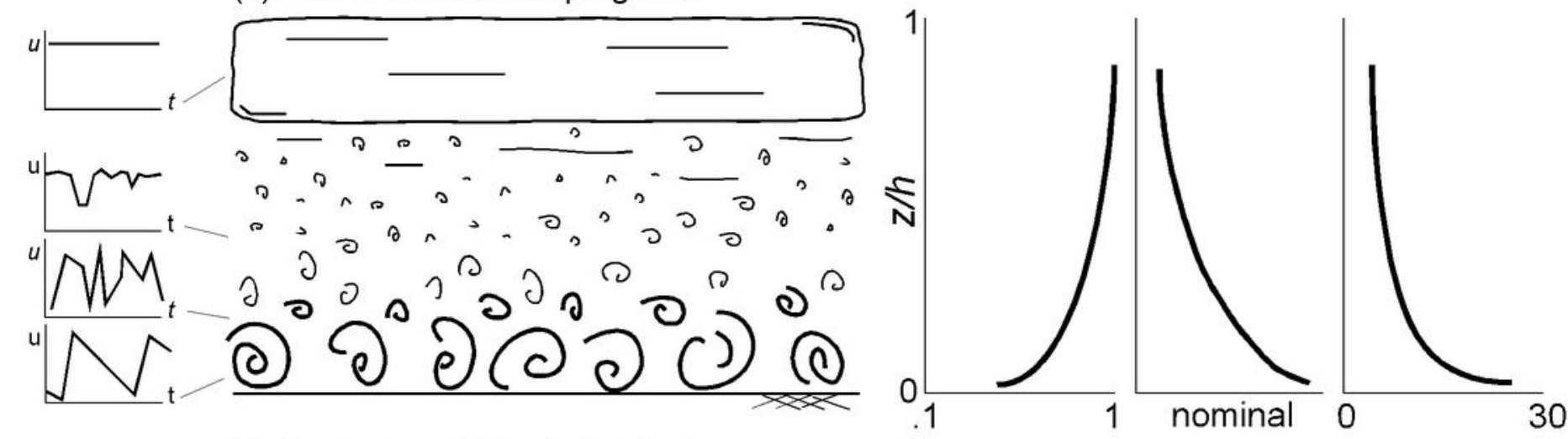

(d) Upper transitional plug flow

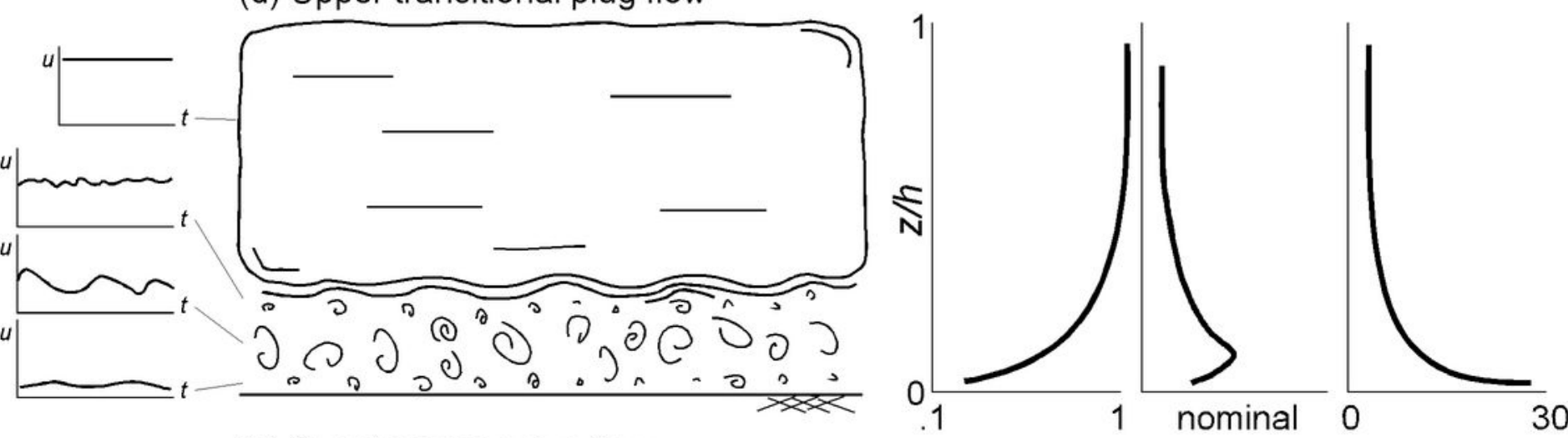

(e) Quasi-laminar plug flow

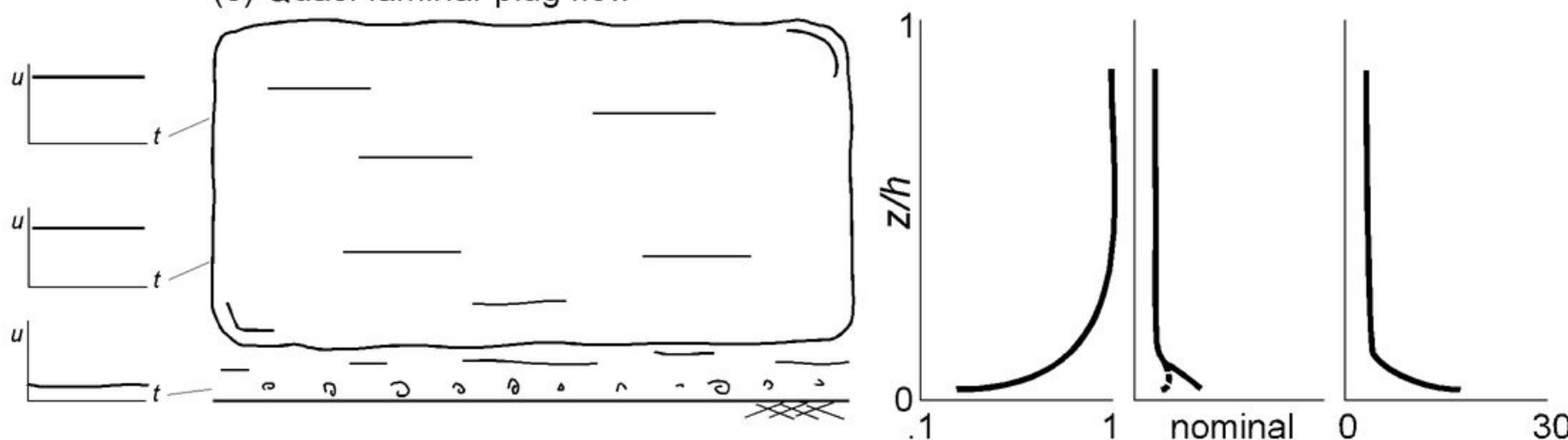


A) Turbulent flow (run 5-3)
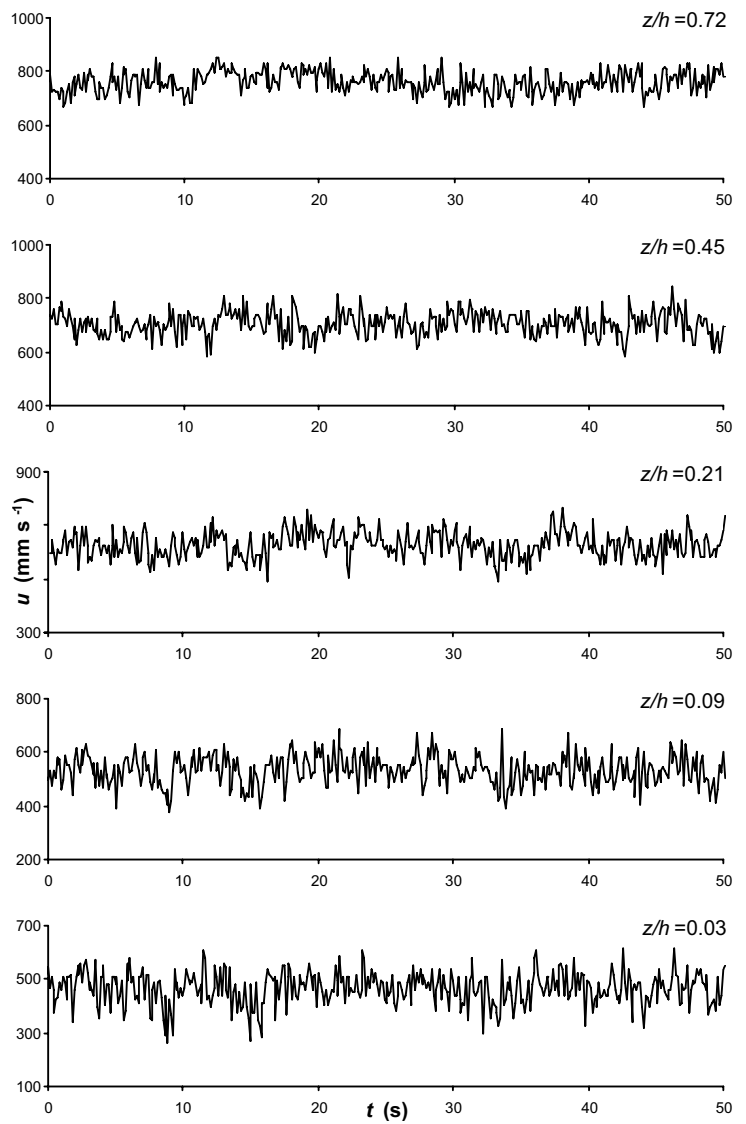

B) Turbulence-enhanced transitional flow (run 5-9)
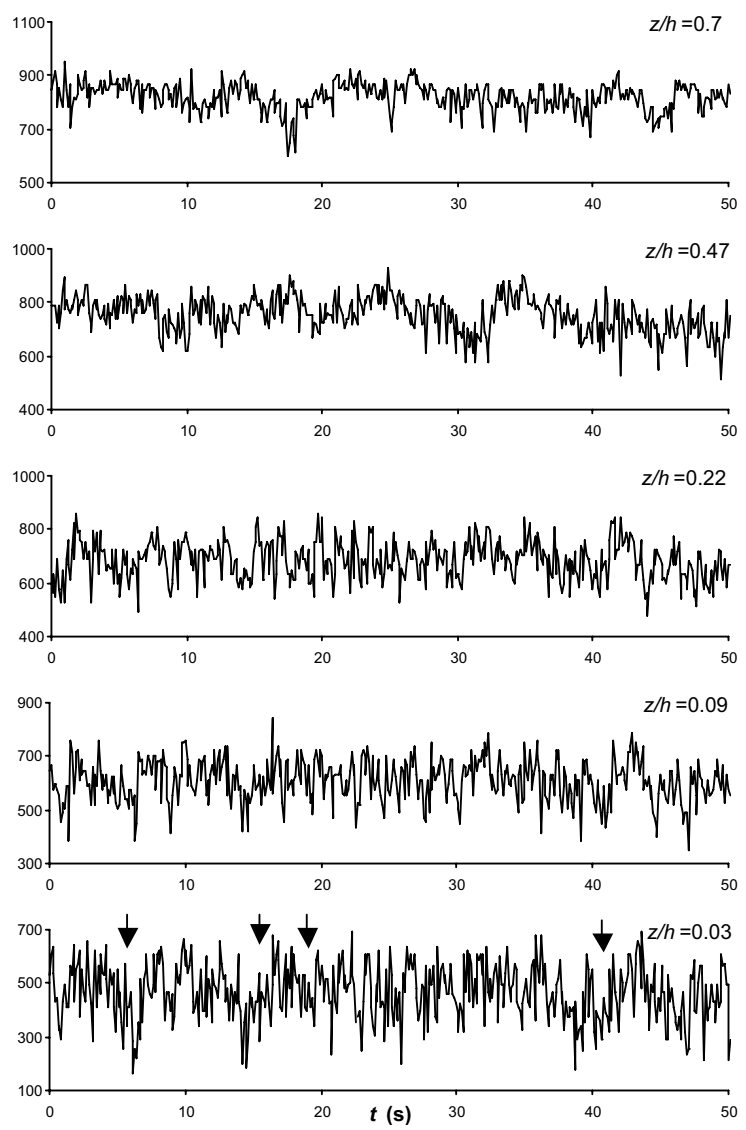
A) Run 2-10
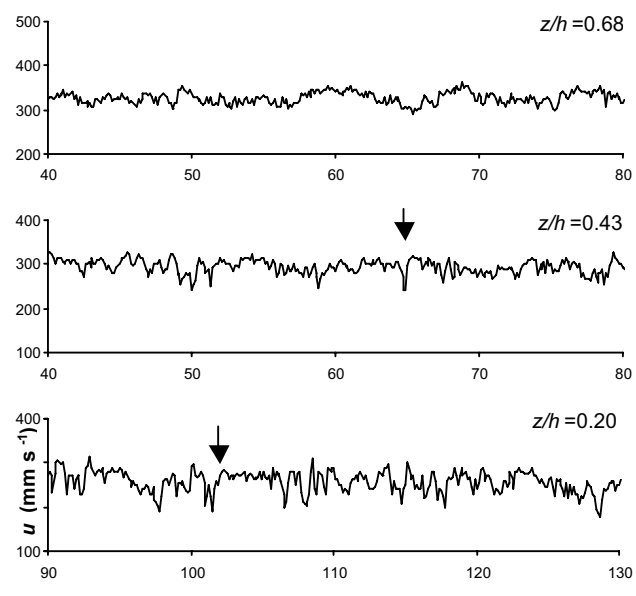

$\underbrace{200}_{90} \underbrace{{ }_{100}^{400}}_{100} \underbrace{z / h=0.11}_{110}$

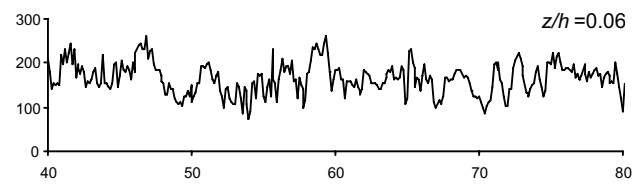

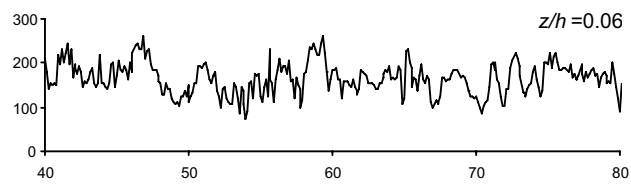

(is)
B) Run 4-17
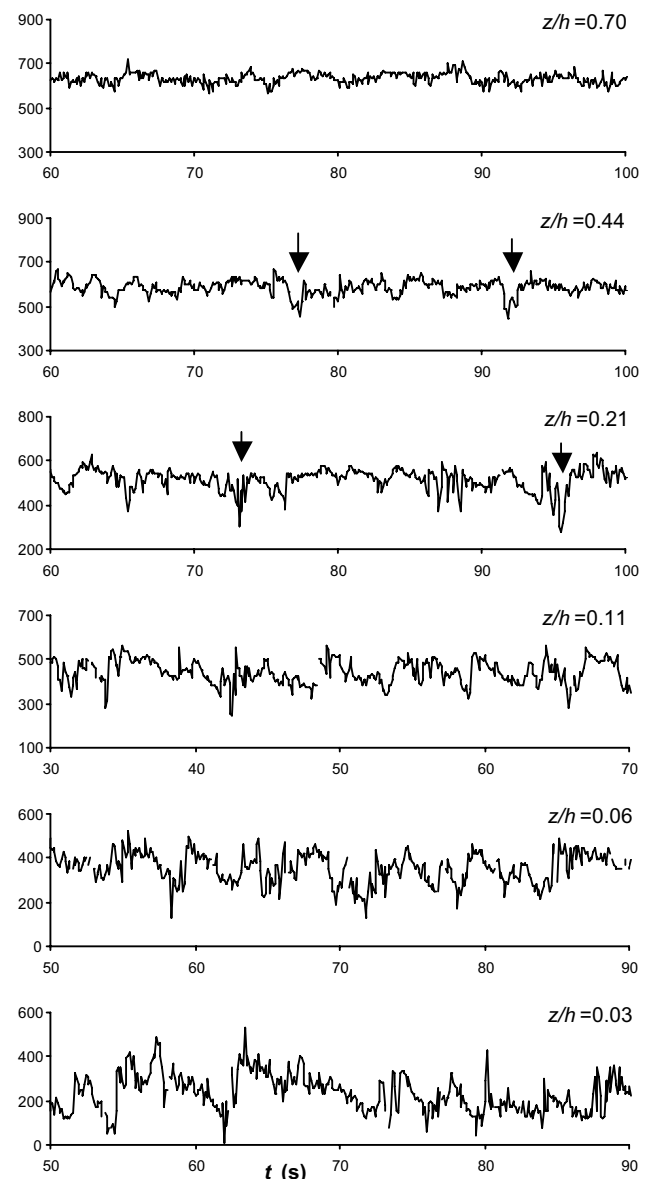

C) Run 7-20
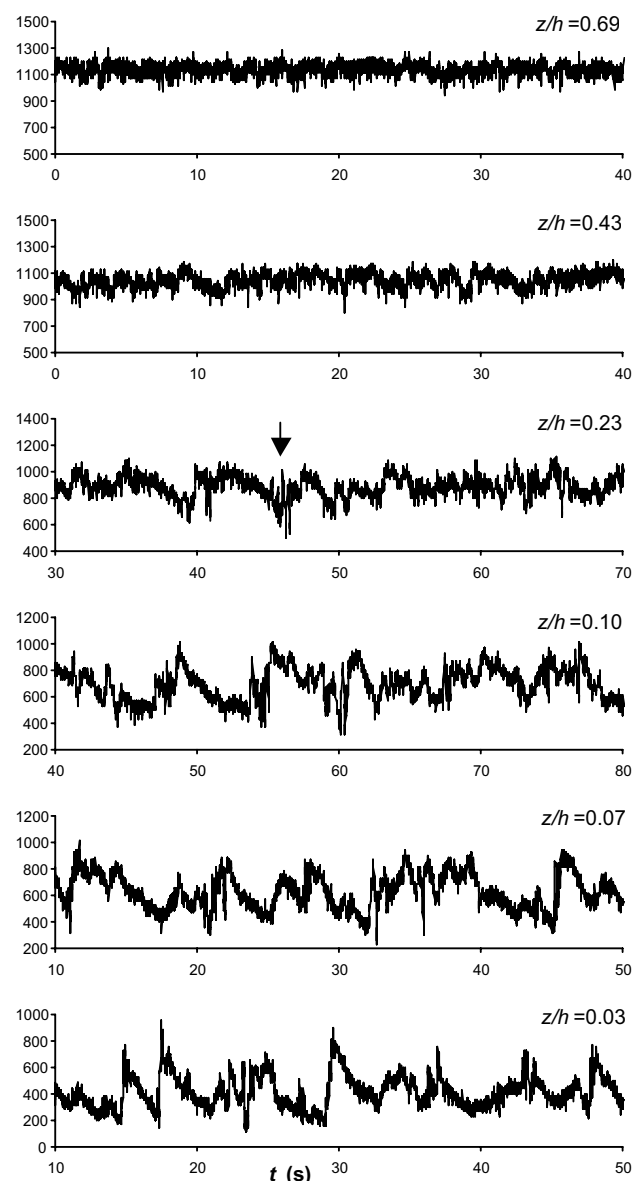

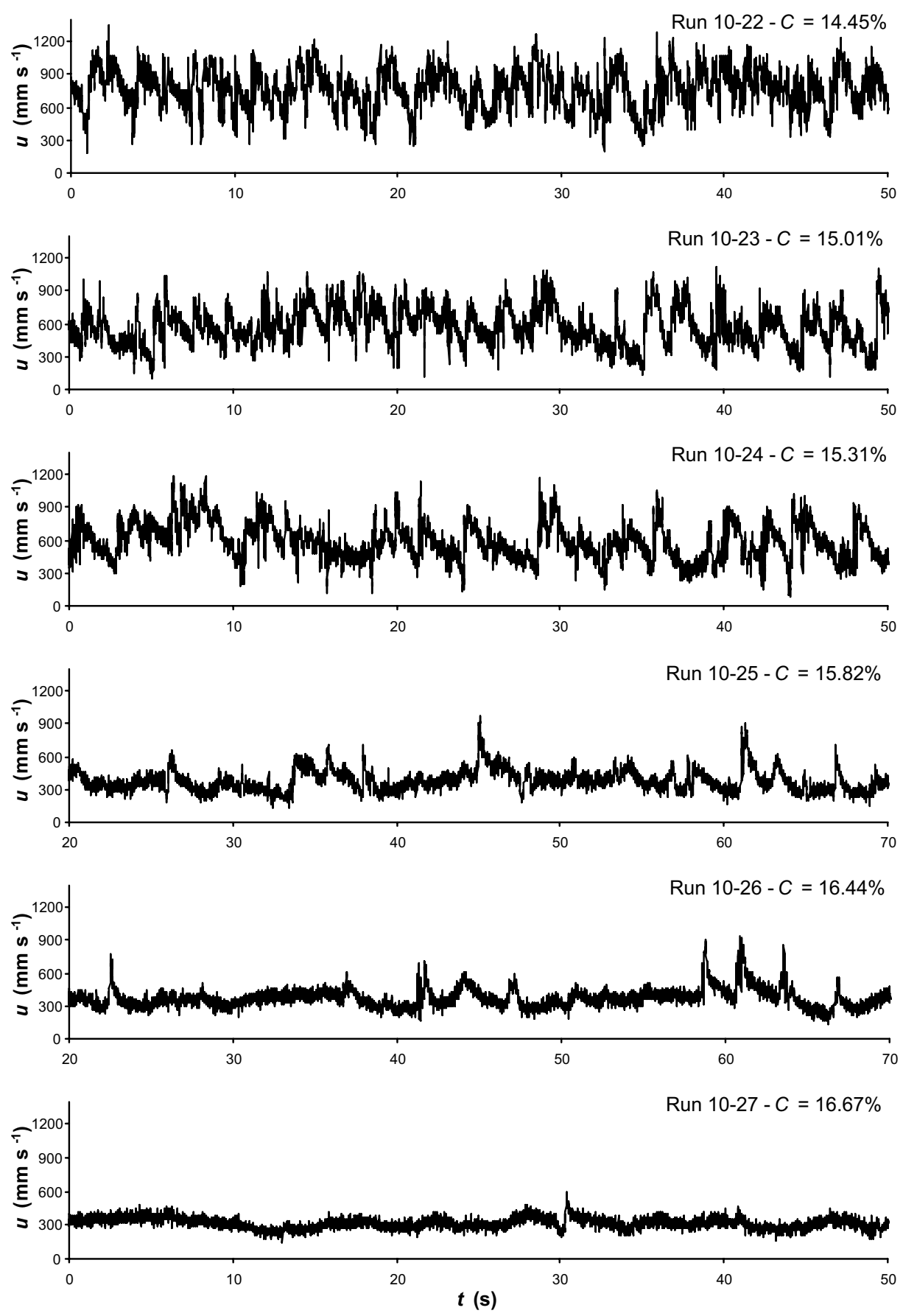
A) Upper transitional plug flow (run 6-20)
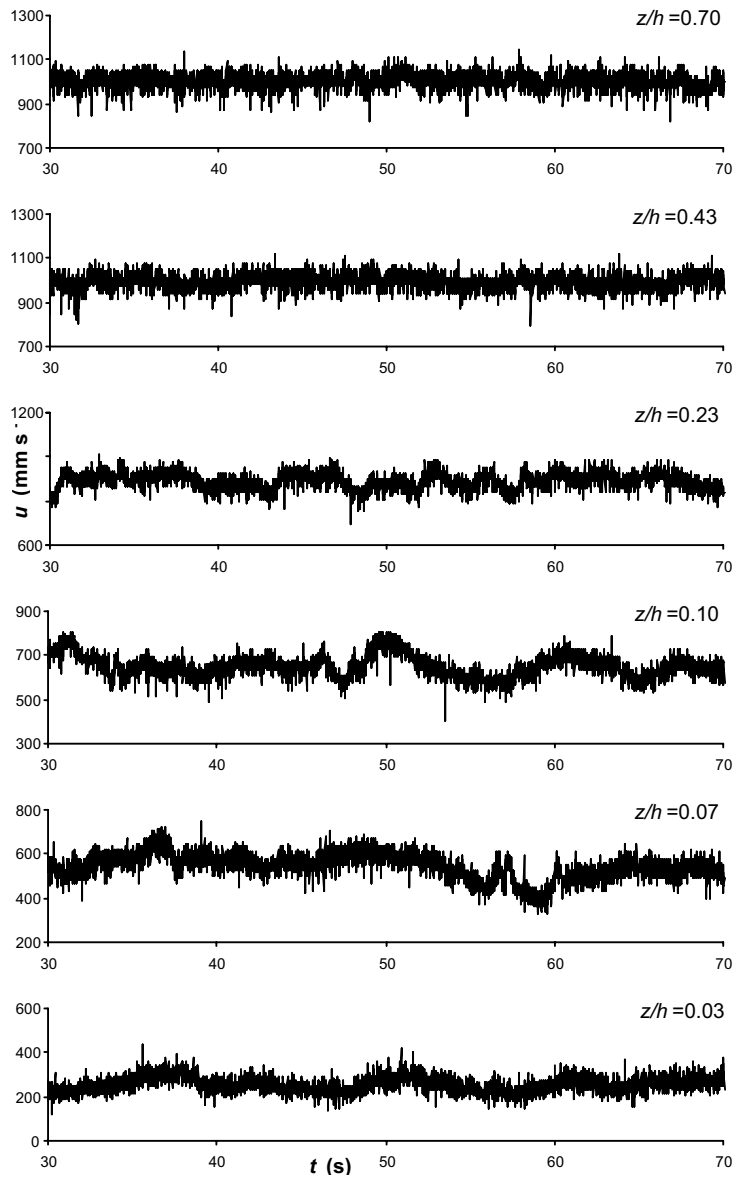

B) Quasi-laminar plug flow (run 6-24)

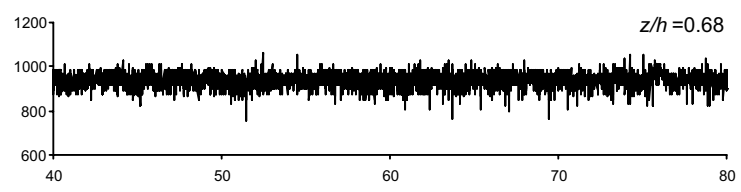

$\mathrm{z} / \mathrm{h}=0.42$
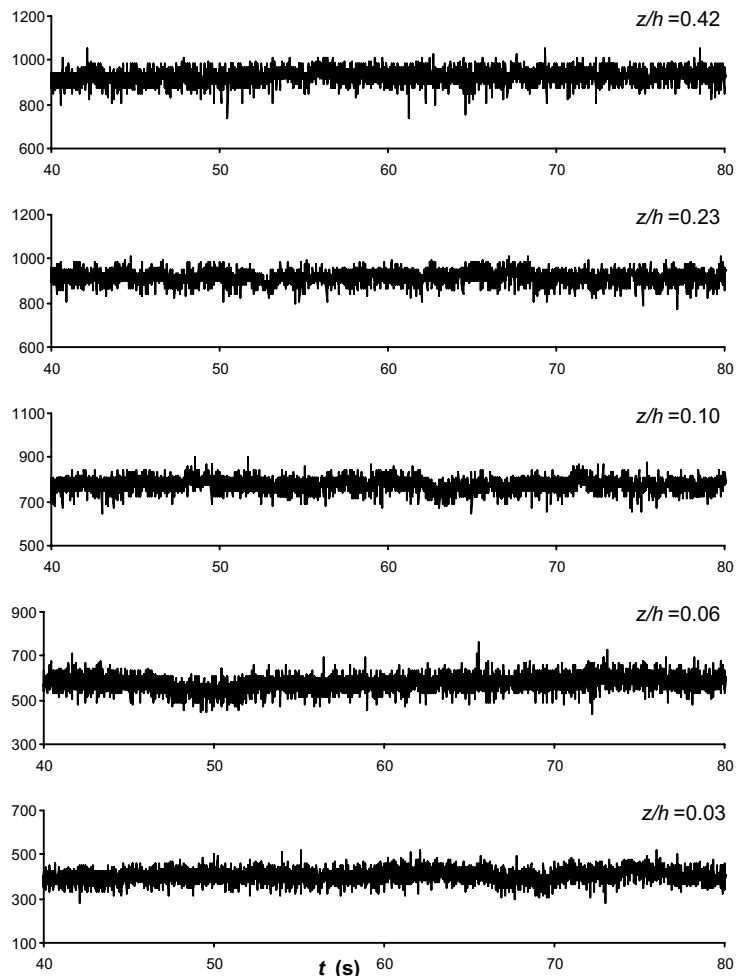


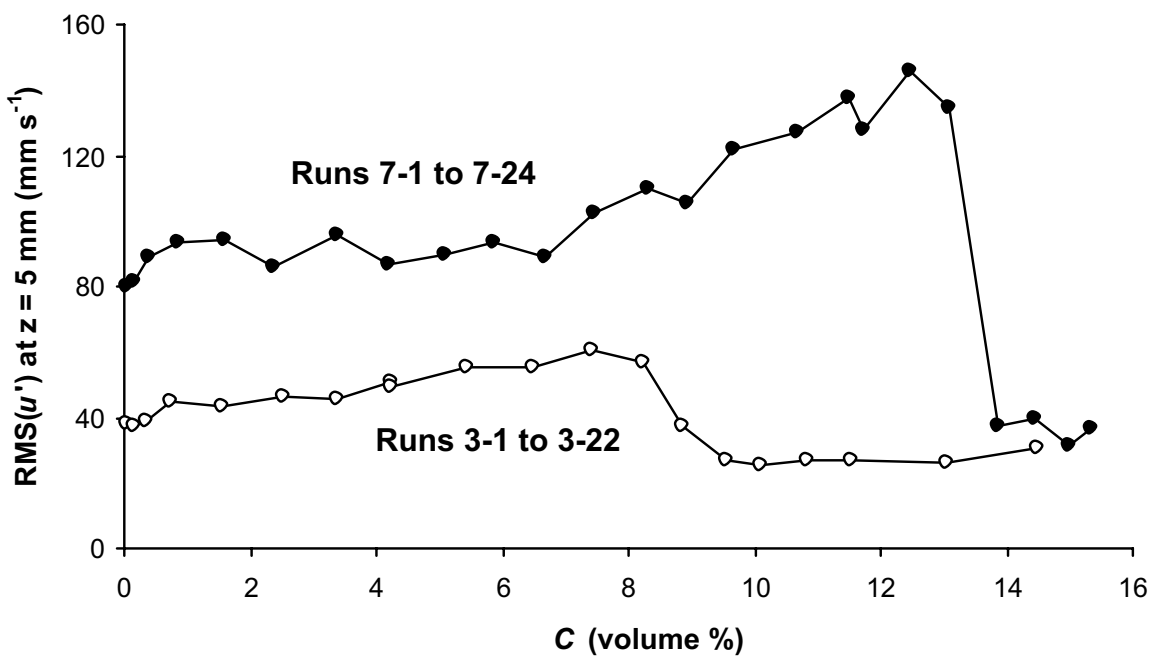




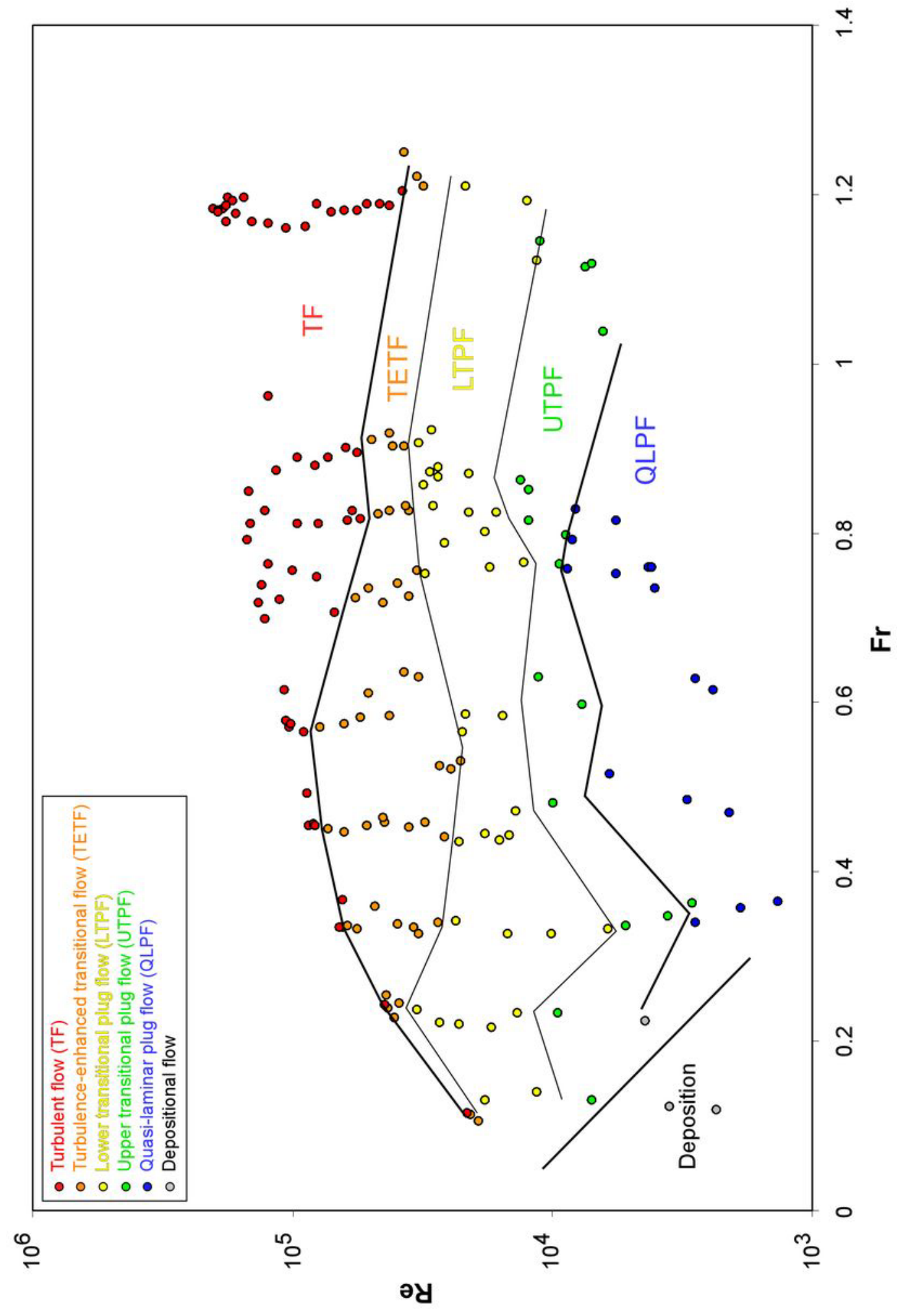


Wang \& Plate (1996): This study:

- Turbulent flow

- Transitional flow

+ Laminar plug flow

$\mathrm{TF}=$ turbulent flow

TETF = turbulence-enhanced transitional flow

LTPF $=$ lower transitional plug flow

UTPF = upper transitional plug flow

QLPF $=$ quasi-laminar plug flow

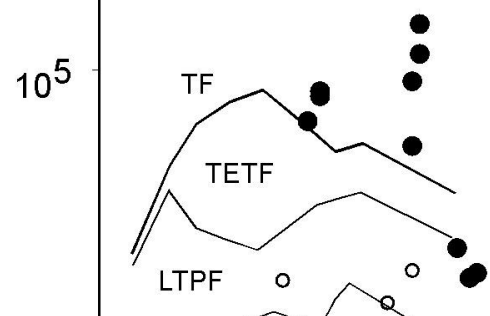

$10^{4}$

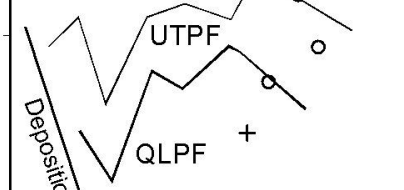

0

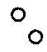


I Mobile fluid mud, Eel river (Traykovski et al. 2000)

$\multimap$ Cohesive turbidity current, laboratory (Felix et al. 2005)

$\longrightarrow$ Subaqueous hyperconcentrated density flow, laboratory (Scarlatos \& Wilder 1990)

× Subaqueous fluid mud flow, laboratory (Van Kessel \& Kranenburg 1996)

Subaerial mudflow, laboratory (Huang \& García 1998)

A Muddy underflows, Yellow and Wei river (Wan 1982); -mean in center of river

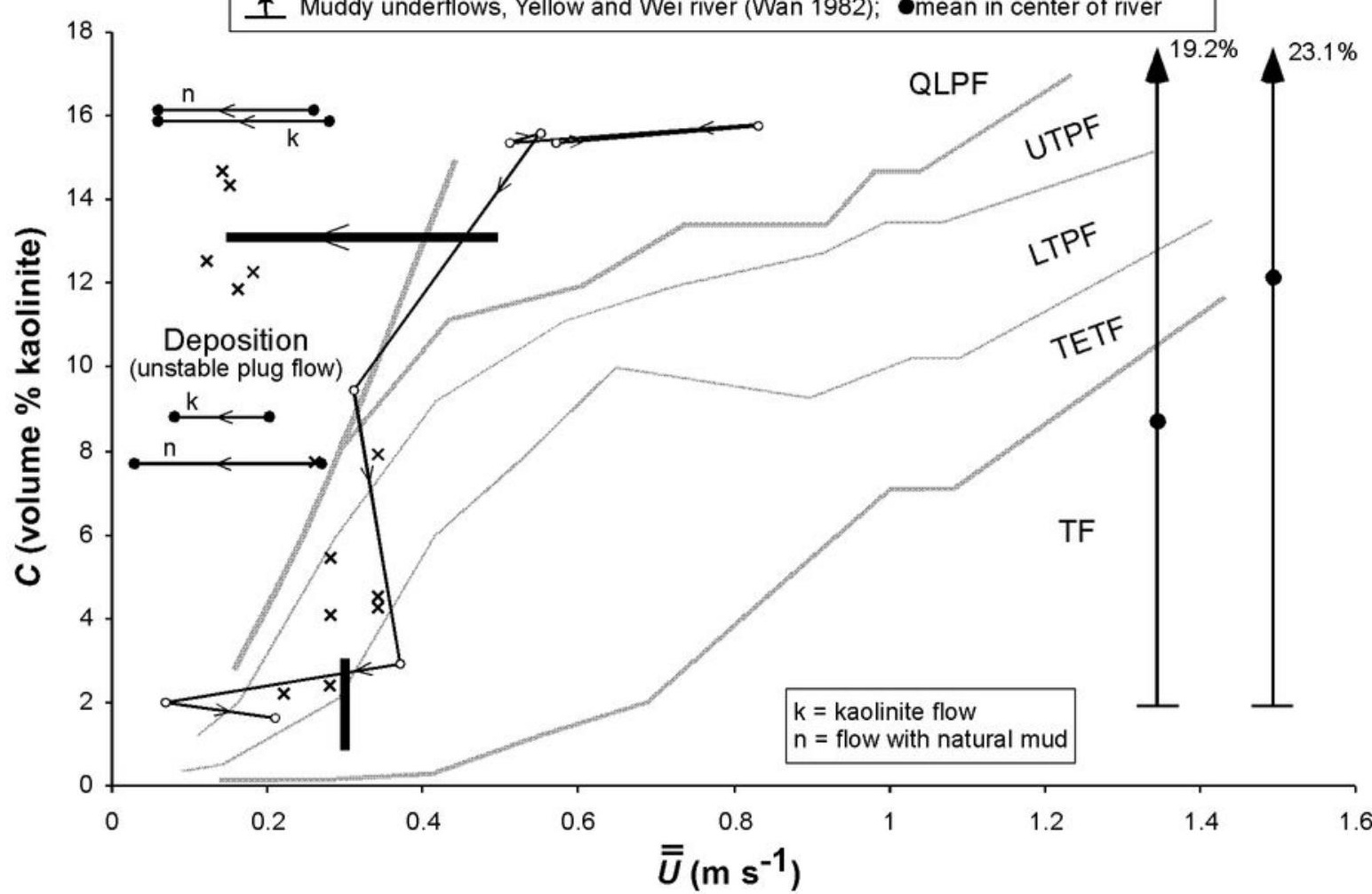


Table 1 - Experimental parameters

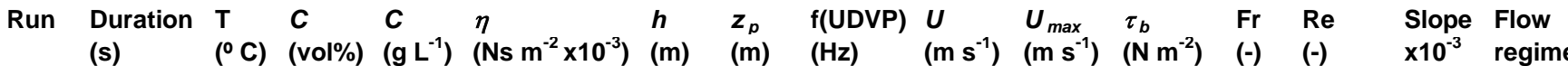

\begin{tabular}{|c|c|c|c|c|c|c|c|c|c|c|c|c|c|c|c|}
\hline $1-1$ & 165 & 201 & 0.04 & 12 & 1000 & 0.150 & & 8 & 0,142 & 0.164 & - & 0.12 & 21281 & 0.00 & TF \\
\hline $1-2$ & 165 & 20 & 0.15 & 4.0 & 1.004 & 0.149 & & 8 & 0.138 & 0.162 & - & 0.11 & 20590 & 0.00 & TETF \\
\hline $1-3$ & 165 & 19.9 & 0.34 & 8.8 & 1.014 & 0.149 & & 8 & 0.129 & 0.151 & - & 0.11 & 19107 & 0.00 & TETF \\
\hline $1-4$ & 165 & 19.9 & 0.74 & 19.4 & 1.055 & 0.149 & 0.117 & 8 & 0.160 & 0.184 & - & 0.13 & 17979 & 0.00 & LTPF \\
\hline $1-5$ & 165 & 19.8 & 1.53 & 39.8 & 1.184 & 0.151 & 0.077 & 8 & 0.172 & 0.192 & - & 0.14 & 11476 & 0.00 & LTPF \\
\hline $1-6$ & 155 & 19.9 & 2.32 & 60.4 & 1.371 & 0.153 & 0.058 & 8 & 0.161 & 0.181 & - & 0.13 & 7065 & 0.00 & UTPF \\
\hline $1-7$ & 165 & 20 & 3.18 & 82.7 & 1.628 & 0.154 & 0.036 & 8 & 0.152 & 0.176 & - & 0.12 & 3531 & 0.00 & QLPF(d) \\
\hline $1-10$ & 165 & 20.1 & 5.33 & 138.5 & 2.494 & 0.158 & 0.036 & 8 & 0.149 & 0.169 & - & 0.12 & 2334 & 0.00 & $\operatorname{QLPF(d)}$ \\
\hline $2-1$ & 156 & 20 & 0.05 & 1.4 & 1.001 & 0.149 & & 8 & 0.294 & 0.338 & 0.26 & 0.24 & 43853 & 0.18 & TF \\
\hline $2-2$ & 156 & 20 & 0.17 & 4.5 & 1.005 & 0.148 & & 8 & 0.289 & 0.333 & 0.26 & 0.24 & 42691 & 0.18 & TETF \\
\hline $2-3$ & 156 & 19.9 & 0.39 & 10.1 & 1.018 & 0.148 & - & 8 & 0.276 & 0.321 & 0.26 & 0.23 & 40435 & 0.18 & TETF \\
\hline $2-4$ & 156 & 19.9 & 0.82 & 21.3 & 1.064 & 0.148 & & 8 & 0.309 & 0.355 & 0.27 & 0.26 & 43533 & 0.18 & TETF \\
\hline $2-5$ & 156 & 198 & 162 & 422 & 1.203 & 0.151 & & 8 & 0,300 & 0.344 & 0.28 & 0.25 & 38586 & 0.18 & TETF \\
\hline $2-6$ & 156 & 19.9 & 2.43 & 63.3 & 1.401 & 0.152 & & 8 & 0.292 & 0.336 & 0.28 & 0.24 & 32952 & 0.18 & LTPF \\
\hline $2-7$ & 156 & 20.1 & 3.27 & 85.0 & 1.658 & 0.154 & & 8 & 0.275 & 0.318 & 0.29 & 0.22 & 26890 & 0.18 & LTPF \\
\hline $2-8$ & 156 & 20 & 4.10 & 106.6 & 1.962 & 0.155 & & 8 & 0.272 & 0.313 & 0.29 & 0.22 & 22889 & 0.18 & LTPF \\
\hline $2-9$ & 156 & 20 & 4.14 & 107.8 & 1.980 & 0.155 & 0.117 & 8 & 0.269 & 0.313 & 0.29 & 0.22 & 16955 & 0.18 & LTPF \\
\hline $2-10$ & 156 & 20.1 & 5.36 & 139.4 & 2.510 & 0.158 & 0.107 & 8 & 0.292 & 0.335 & 0.30 & 0.23 & 13531 & 0.18 & LTPF \\
\hline $2-11$ & 156 & 20.2 & 6.45 & 167.8 & 3.063 & 0.158 & 0.090 & 8 & 0.293 & 0.333 & 0.31 & 0.24 & 9500 & 0.18 & UTPF \\
\hline $2-12$ & 156 & 21 & 7.39 & 192.1 & 3.588 & 0.158 & 0.050 & 8 & 0.281 & 0.319 & 0.31 & 0.23 & 4378 & 0.18 & QLPF(d) \\
\hline $3-1$ & 135 & 20 & 0.05 & 1.2 & 1.000 & 0.145 & & 9 & 0.439 & 0.504 & 0.26 & 0.37 & 63599 & 0.18 & TF (W) \\
\hline 3-2 & 165 & 19 & 0.15 & 4.0 & 1.004 & 0.157 & & 8 & 0.416 & 0.457 & 0.45 & 0.34 & 65256 & 0.29 & TF \\
\hline 3-3 & 165 & 20.1 & 0.37 & 9.6 & 1.017 & 0.155 & & 8 & 0.414 & 0.458 & 0.44 & 0.34 & 63473 & 0.29 & TETF \\
\hline 3-4 & 156 & 18.7 & 0.73 & 18.9 & 1.053 & 0.154 & & 8 & 0.416 & 0.459 & 0.28 & 0.34 & 61563 & 0.18 & TETF \\
\hline 3-5 & 156 & 20.6 & 1.54 & 40.0 & 1.185 & 0.156 & & 8 & 0.413 & 0.455 & 0.28 & 0.33 & 55711 & 0.18 & TETF \\
\hline $3-6$ & 135 & 19.9 & 2.54 & 65.9 & 1.429 & 0.150 & & 9 & 0.438 & 0.499 & 0.28 & 0.36 & 47847 & 0.18 & TETF \\
\hline 3-7 & 135 & 20.1 & 3.37 & 87.6 & 1.692 & 0.152 & & 9 & 0.415 & 0.475 & 0.28 & 0.34 & 39256 & 0.18 & TETF \\
\hline 3-8 & 135 & 20 & 4.22 & 109.6 & 2.008 & 0.155 & & 9 & 0.413 & 0.466 & 0.29 & 0.34 & 34052 & 0.18 & TETF \\
\hline 3-9 & 135 & 20 & 4.23 & 109.9 & 2.013 & 0.153 & & 9 & 0.402 & 0.462 & 0.29 & 0.33 & 32655 & 0.18 & TETF \\
\hline 3-10 & 135 & 20.1 & 5.45 & 141.8 & 2.553 & 0.153 & & 9 & 0.419 & 0.478 & 0.30 & 0.34 & 27323 & 0.18 & TETF \\
\hline 3-11 & 135 & 20.2 & 6.50 & 168.9 & 3.086 & 0.155 & & 9 & 0.424 & 0.487 & 0.30 & 0.34 & 23485 & 0.18 & LTPF \\
\hline 3-12 & 135 & 21 & 7.43 & 193.1 & 3.611 & 0.155 & 0.117 & 9 & 0.405 & 0.469 & 0.31 & 0.33 & 14691 & 0.18 & LTPF \\
\hline 3-13 & 135 & 21.2 & 8.24 & 214.1 & 4.107 & 0.158 & 0.090 & 9 & 0.408 & 0.453 & 0.32 & 0.33 & 10120 & 0.18 & LTPF \\
\hline 3-14 & 135 & 21.4 & 8.87 & 230.7 & 4.520 & 0.159 & 0.058 & 9 & 0.416 & 0.455 & 0.32 & 0.33 & 6096 & 0.18 & LTPF \\
\hline 3-15 & 135 & 21.5 & 9.57 & 248.7 & 4.994 & 0.155 & 0.036 & 9 & 0.430 & 0.470 & 0.32 & 0.35 & 3574 & 0.18 & UTPF \\
\hline $3-16$ & 135 & 19.9 & 10.11 & 262.8 & 5.382 & 0.156 & 0.058 & 9 & 0.417 & 0.473 & 0.32 & 0.34 & 5221 & 0.18 & UTPF \\
\hline 3-17 & 135 & 20.5 & 10.83 & 281.6 & 5.922 & 0.157 & 0.032 & 9 & 0.453 & 0.501 & 0.33 & 0.37 & 2872 & 0.18 & UTPF \\
\hline 3-18 & 135 & 21 & 11.53 & 299.7 & 6.465 & 0.159 & 0.036 & 9 & 0.427 & 0.459 & 0.33 & 0.34 & 2816 & 0.18 & QLPF \\
\hline $3-20$ & 135 & 23 & 13.03 & 338.8 & 7.714 & 0.156 & 0.027 & 9 & 0.444 & 0.471 & 0.33 & 0.36 & 1878 & 0.18 & QLPF \\
\hline 3-22 & 118 & 24.7 & 14.47 & 376.2 & 9.006 & 0.155 & 0.022 & 11 & 0.451 & 0.468 & 0.34 & 0.37 & 1357 & 0.18 & QLPF \\
\hline $4-1$ & $156-165$ & 14.5 & 0.03 & 0.8 & 1.000 & 0.147 & & 8 & 0.593 & 0.667 & 0.42 & 0.49 & 87176 & 0.29 & TF \\
\hline $4-2$ & 156 & 19.1 & 0.16 & 4.0 & 1.004 & 0.154 & & 8 & 0.559 & 0.618 & 0.44 & 0.46 & 86023 & 0.29 & TF \\
\hline $4-3$ & 156 & 20 & 0.38 & 9.8 & 1.017 & 0.151 & 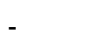 & 8 & 0.557 & 0.620 & 0.43 & 0.46 & 83182 & 0.29 & TF \\
\hline $4-4$ & 156 & 18.6 & 0.74 & 19.3 & 1.054 & 0.152 & & 8 & 0.557 & 0.617 & 0.44 & 0.46 & 81301 & 0.29 & TF \\
\hline $4-5$ & 156 & 20.5 & 1.56 & 40.6 & 1.190 & 0.152 & & 8 & 0.553 & 0.615 & 0.44 & 0.45 & 72356 & 0.29 & TETF \\
\hline $4-6$ & 156 & 19.7 & 2.32 & 60.4 & 1.371 & 0.152 & & 8 & 0.546 & 0.617 & 0.45 & 0.45 & 62834 & 0.29 & TETF \\
\hline $4-7$ & 156 & 22.1 & 3.32 & 86.3 & 1.675 & 0.149 & & 8 & 0.551 & 0.634 & 0.45 & 0.46 & 51669 & 0.29 & TETF \\
\hline $4-8$ & 156 & 19.9 & 4.18 & 108.7 & 1.995 & 0.148 & & 8 & 0.553 & 0.635 & 0.45 & 0.46 & 43806 & 0.29 & TETF \\
\hline $4-9$ & 118 & 19.8 & 4.26 & 110.8 & 2.027 & 0.150 & & 11 & 0.565 & 0.640 & 0.46 & 0.47 & 44689 & 0.29 & TETF \\
\hline $4-10$ & 118 & 20 & 549 & 1428 & 2572 & 0152 & & 11 & 0,553 & 0628 & 0.47 & 0.45 & 35566 & 029 & TETF \\
\hline 4-11 & 118 & 20.2 & 6.54 & 170.1 & 3.111 & 0.154 & & 11 & 0.564 & 0.643 & 0.48 & 0.46 & 30869 & 0.29 & TETF \\
\hline $4-12$ & 118 & 21 & 7.47 & 194.2 & 3.637 & 0.154 & & 11 & 0.544 & 0.625 & 0.49 & 0.44 & 25780 & 0.29 & $\begin{array}{l}\text { TETF } \\
\text { The }\end{array}$ \\
\hline $4-13$ & 118 & 21.2 & 8.28 & 215.3 & 4.136 & 0.154 & & 11 & 0.536 & 0.614 & 0.50 & 0.44 & 22607 & 0.29 & LTPF \\
\hline $4-14$ & 118 & 214 & 8.93 & 2321 & 4.558 & 0,156 & 0.117 & 11 & 0.542 & 0,610 & 0.51 & 0.44 & 15909 & 0,29 & LTPF \\
\hline 4-15 & 118 & 21.5 & 9.61 & 249.9 & 5.028 & 0.154 & 0.117 & 11 & 0.547 & 0.617 & 0.50 & 0.44 & 14679 & 0.29 & LTPF \\
\hline 4-16 & 118 & 19.9 & 10.17 & 264.4 & 5.42 & 0.154 & & 11 & 0.5 & 0.6 & 0.51 & 0.45 & 18064 & 0.29 & LTPF \\
\hline 4-17 & 118 & 20.4 & 10.69 & 277.9 & 5.814 & 0.154 & 0.117 & 11 & 0.581 & 0.650 & 0.51 & 0.47 & 13681 & 0.29 & LTPF \\
\hline $4-18$ & 118 & 20.9 & 11.54 & 299.9 & 6.472 & 0.156 & 0.090 & 11 & 0.597 & 0.664 & 0.52 & 0.48 & 9834 & 0.29 & UTPF \\
\hline $4-19$ & 118 & 23.3 & 12.40 & 322.4 & 7.178 & 0.147 & 0.058 & & 0.621 & 0.674 & 0.50 & 0.52 & 6014 & 0.29 & QLPF \\
\hline $4-20$ & 111 & 23.3 & 13.02 & 338.4 & 7.702 & 0.154 & 0.032 & 11 & 0.598 & 0.643 & 0.53 & 0.49 & 3002 & 0.29 & QLPF \\
\hline
\end{tabular}




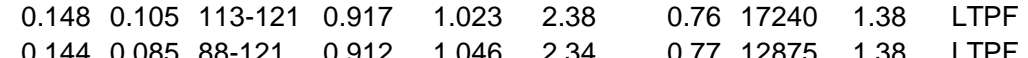

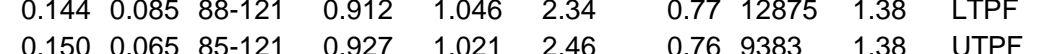

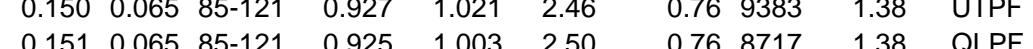
$\begin{array}{llllllllll}0.151 & 0.045 & 85-121 & 0.916 & 0.968 & 2.52 & 0.75 & 5643 & 1.38 & \text { QLPF }\end{array}$

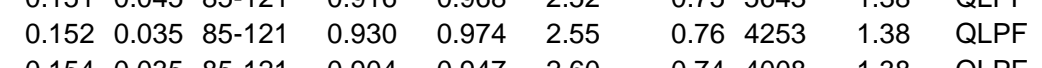

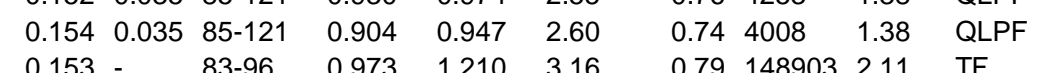
$\begin{array}{llllllllll}0.153- & 83-96 & 0.973 & 1.210 & 3.16 & 0.79 & 148903 & 2.11 & \text { TF } \\ 0.148 & & & 0.979 & 1.119 & 3.07 & 0.81 & 144673 & 2.11 & \text { TF }\end{array}$

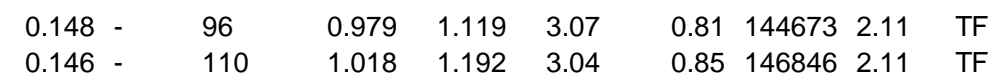
$\begin{array}{llllllllll}0.150 & 96 & 1.031 & 1.200 & 3.14 & 0.85 & 146884 & 2.11 & \text { TF }\end{array}$ $\begin{array}{lllllllll}0.149- & 83-115 & 1.000 & 1.142 & 3.16 & 0.83 & 127418 & 2.11 & \text { TF }\end{array}$

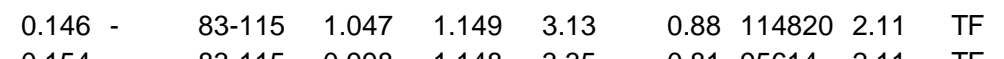
$\begin{array}{lllllllll}0.154- & 83-115 & 0.998 & 1.148 & 3.35 & 0.81 & 95614 & 2.11 & \text { TF } \\ 0.151 & 83-115 & 0.989 & 1.158 & 3.33 & 0.81 & 79637 & 2.11 & \text { TF }\end{array}$ $\begin{array}{lllllllll}0.151 & 83-115 & 0.989 & 1.158 & 3.33 & 0.81 & 79637 & 2.11 & \text { TF }\end{array}$ $\begin{array}{lllllllll}0.141- & 83-115 & 0.959 & 1.140 & 3.15 & 0.82 & 61453 & 2.11 & \text { TF } \\ 0.148 & 83-115 & 0.997 & 1.182 & 3.34 & 0.83 & 58758 & 2.11 & \text { TF }\end{array}$ $\begin{array}{lllllllll}0.148 & 83-115 & 0.997 & 1.182 & 3.34 & 0.83 & 58758 & 2.11 & \text { TF } \\ 0.155 & 83-115 & 1.010 & 1.164 & 3.54 & 0.82 & 54467 & 2.11 & \text { TF }\end{array}$ $\begin{array}{lllllllll}0.155- & 83-115 & 1.010 & 1.164 & 3.54 & 0.82 & 54467 & 2.11 & \text { TF } \\ 0.151- & 83-115 & 1.003 & 1.159 & 3.49 & 0.82 & 46636 & 2.11 & \text { TETF }\end{array}$ $\begin{array}{lllllllll}0.151 & 83-115 & 1.003 & 1.159 & 3.49 & 0.82 & 46636 & 2.11 & \text { TETF } \\ 0.153 & 83-115 & 1.013 & 1.164 & 3.58 & 0.83 & 42317 & 2.11 & \text { TETF }\end{array}$ $\begin{array}{llllllllll}0.144- & 83-115 & 0.985 & 1.185 & 3.40 & 0.83 & 35569 & 2.11 & \text { TETF } \\ 0.145 & -1.115 & 1.029 & 1.175 & 3.70 & 0.83 & 3605 & 2.11 & \text { TETF }\end{array}$ $\begin{array}{llllllllll}0.155 & - & 83-115 & 1.029 & 1.175 & 3.70 & 0.83 & 36405 & 2.11 & \text { TETF }\end{array}$ $\begin{array}{lllllllll}0.115- & 83-115 & 1.029 & 1.175 & 3.70 & 0.83 & 36405 & 2.11 & \text { TETF } \\ 0.149- & 113-126 & 1.037 & 1.204 & 3.60 & 0.86 & 31207 & 2.11 & \text { LTPF }\end{array}$ $\begin{array}{lllllllll}0.149- & 113-126 & 1.037 & 1.204 & 3.60 & 0.86 & 31207 & 2.11 & \text { LTPF } \\ 0.143- & 113-126 & 1.041 & 1.198 & 3.50 & 0.88 & 27386 & 2.11 & \text { LTPF } \\ 0.155- & 113-126 & 1.028 & 1.154 & 3.80 & 0.83 & 28520 & 2.11 & \text { LTPF }\end{array}$ 
$\begin{array}{llllll}7-19 & 79-88 & 22.5 & 12.47 & 324.3 & 7.238 \\ 7-20 & 79-113 & 25.6 & \end{array}$ $\begin{array}{lllllll}7-19 & 79-88 & 22.5 & 12.47 & 324.3 & 7.238 \\ 7-21 & 83-118 & 25.6 & 13.11 & 340.7 & 7.780\end{array}$ $\begin{array}{lllllll}7-23 & 83-118 & 24.3 & 14.99 & 389.8 & 9.500\end{array}$ $\begin{array}{llllll}7-24 & 83-118 & 28 & 15.33 & 398.5 & 9.819\end{array}$ $\begin{array}{llllll}8-6 & 87-104 & 21.5 & 2.40 & 62.5 & 1.392 \\ 8-7 & 75-79 & 21.3 & 3.38 & 8.0 & 1.697\end{array}$ $\begin{array}{llllll}8-7 & 75-79 & 21.3 & 3.38 & 88.0 & 1.697\end{array}$ $\begin{array}{llllll}8-8 & 87 & 20.9 & 4.21 & 109.4 & 2.006 \\ 8-9 & 87 & 23.7 & 5.08 & 13.1 & 2.380\end{array}$ $\begin{array}{llllll}8-9 & 87 & 23.7 & 5.08 & 132.1 & 2.380 \\ 8-10 & 87 & 20.7 & 584 & 15.7 & 2.74\end{array}$ $\begin{array}{lllllll}8-10 & 87 & 20.7 & 5.84 & 151.7 & 2.741 \\ 8-11 & 87 & & 23.7 & 6.68 & 173.7 & 3.185\end{array}$ $\begin{array}{lllllll}8-13 & 87 & 24.2 & 8.40 & 13.9 & 3.629\end{array}$ $\begin{array}{llllllll}8-14 & 87 & 20.8 & 8.94 & 2325 & 4.567\end{array}$ $\begin{array}{llllll}8-15 & 87 & 23.5 & 9.66 & 251.0 & 5.058\end{array}$ $\begin{array}{lllllll}8-16 & 79 & 22.3 & 10.67 & 277.5 & 5.000\end{array}$ $\begin{array}{lllllll}8-16 & 79 & 22.3 & 1.67 & 27.5 & 5.800 \\ 8-17 & 79 & & 26.1 & 11.48 & 298.5 & 6.427\end{array}$ 8-18 $79 \quad 23.2 \quad 11.74 \quad 305.2 \quad 6.634$ $\begin{array}{lllllll}8-20 & 79 & 25 & 13.08 & 340.1 & 7.758\end{array}$ $\begin{array}{llllll}8-21 & 79-109 & 22.7 & 13.85 & 360.2 & 8.443\end{array}$ $\begin{array}{llllll}8-23 & 79-118 & 23.4 & 15.00 & 390.0 & 9.505\end{array}$ $\begin{array}{lllllll}8-24 & 79-118 & 27.5 & 15.30 & 397.9 & 9.797\end{array}$ $\begin{array}{llllll}9-1 & 76-87 & 13.8 & 0.03 & 0.8 & 1.000 \\ 9-2 & 76-87 & 19.5 & 0.17 & 4.4 & 1.004\end{array}$ $\begin{array}{lllllll}9.3 & 76-87 & 20 & 0.40 & 10.4 & 1.019\end{array}$ $\begin{array}{llllll}9-5 & 76-87 & 17.9 & 1.63 & 42.4 & 1.205\end{array}$ $\begin{array}{llllll}10-1 & 70-87 & 15.5 & 0.03 & 0.8 & 1.000\end{array}$ $\begin{array}{llllll}10-2 & 70-87 & 20.8 & 0.17 & 4.3 & 1.004\end{array}$ $\begin{array}{llllll}10-3 & 70-87 & 21.2 & 0.40 & 10.5 & 1.020\end{array}$ $\begin{array}{llllll}0-4 & 70-87 & 23.6 & 0.85 & 22.0 & 1.068 \\ 0-5 & 70-87 & 22.2 & 1.66 & 43.1 & 1.210\end{array}$ $\begin{array}{llllll}10-6 & 70-87 & 19.8 & 2.59 & 67.5 & 1.446\end{array}$ $\begin{array}{llllll}10-7 & 70-87 & 19.5 & 3.37 & 87.7 & 1.694\end{array}$ $\begin{array}{lllllll}10-7 & 70-87 & 19.5 & 3.37 & 87.7 & 1.694 \\ 10-8 & 70-87 & 22 & 4.24 & 110.2 & 2.018\end{array}$ $\begin{array}{llllll}10-9 & 70-87 & 23.6 & 5.10 & 132.5 & 2.387 \\ 0-10 & 70-87 & 19.5 & 5.82 & 151.4 & 2.735\end{array}$ $\begin{array}{llllll}10-10 & 70-87 & 19.5 & 5.82 & 151.4 & 2.735 \\ 10-11 & 70-87 & 24.6 & 6.70 & 174.2 & 3.196\end{array}$ $\begin{array}{llllll}10-12 & 70-87 & 20 & 7.45 & 93.7 & 3.624 \\ 10-13 & 70-87 & 233 & 830 & 215.7 & 4.144\end{array}$ $\begin{array}{llllll}10-14 & 70-87 & 19.7 & 8.95 & 232.8 & 4.1445\end{array}$ $\begin{array}{llllll}10-15 & 70-87 & 22.6 & 9.66 & 251.3 & 5.064\end{array}$ $\begin{array}{llllll}0-16 & 70-79 & 21 & 10.68 & 277.7 & 5807\end{array}$ $\begin{array}{llllll}10-17 & 70-79 & 25.4 & 11.48 & 298.4 & 6.424\end{array}$ $\begin{array}{llllll}10-18 & 70-79 & 21.8 & 11.70 & 304.2 & 6.603\end{array}$ 10-19 $70-79 \quad 20.2 \quad 12.48 \quad 324.5 \quad 7.245$ $\begin{array}{llllll}10-20 & 70-79 & 23.9 & 13.07 & 339.9 & 7.752\end{array}$ $\begin{array}{llllll}10-21 & 70-79 & 21.5 & 13.92 & 361.9 & 8.503\end{array}$ $\begin{array}{llllll}10-22 & 70-79 & 25 & 14.45 & 375.7 & 8.987\end{array}$ $\begin{array}{llllll}10-23 & 51-79 & 22 & 15.01 & 390.3 & 9.517\end{array}$ $\begin{array}{llllll}10-24 & 51-79 & 27.7 & 15.31 & 398.0 & 9.800\end{array}$ $\begin{array}{llllll}10-25 & 70-113 & 20.4 & 15.82 & 411.2 & 10.298\end{array}$

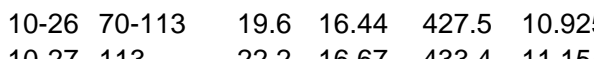
$\begin{array}{llllll}7-20 & 79-113 & 25.6 & 13.11 & 340.7 & 7.780 \\ 7-22 & 83-118 & 23.2 & 13.87 & 360.7 & 8.459 \\ 7-23 & 33-118 & 24.3 & 14.45 & 375.8 & 8.991\end{array}$ $\begin{array}{llllll}8-11 & 87 & 23.7 & 6.68 & 151.7 & 2.741 \\ 8-12 & 87 & 21.7 & 7.46 & 1939 & 3.659\end{array}$ $\begin{array}{llllll}8-19 & 79 & 21.8 & 12.47 & 324.2 & 7.236\end{array}$ $\begin{array}{lllllll}8-22 & 75-113 & 26.1 & 14.45 & 375.7 & 8.989\end{array}$ $\begin{array}{llllll}9-4 & 76-87 & 20 & 0.40 & 10.4 & 1.019\end{array}$ $\begin{array}{llllll}10-11 & 70-87 & 24.6 & 6.70 & 174.2 & 3.196 \\ 10-12 & 70-87 & 20 & 7.45 & 193.7 & 3.624\end{array}$

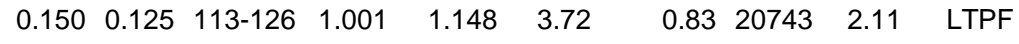

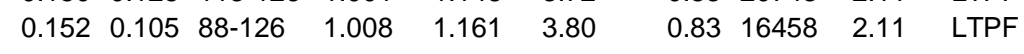

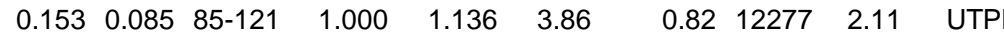

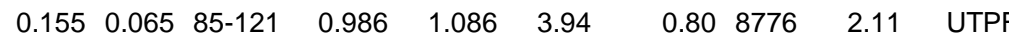

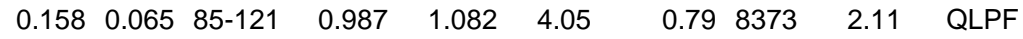
$\begin{array}{llllllllll}0.154 & 0.035 & 85-121 & 0.935 & 1.000 & 3.96 & 0.76 & 4150 & 2.11 & \text { QLPF }\end{array}$ $\begin{array}{lllllllll}0.144- & 96-115 & 1.145 & 1.357 & 4.18 & 0.96 & 122957 & 2.85 & \text { TF } \\ 0.145 & 126-133 & 1.062 & 1.277 & 4.27 & 0.89 & 9517 & 2.85 & \text { F }\end{array}$ $\begin{array}{lllllllll}0.145- & 126-133 & 1.062 & 1.277 & 4.27 & 0.89 & 95617 & 2.85 & \text { TF } \\ 0.146 & 115 & 1.055 & 1.238 & 4.36 & 0.88 & 8200 & 2.85 & \text { TF }\end{array}$ $\begin{array}{lllllllll}0.146- & 115 & 1.055 & 1.238 & 4.36 & 0.88 & 82000 & 2.85 & \text { TF } \\ 0.149 & 115 & 1.076 & 1.275 & 4.50 & 0.89 & 72823 & 2.5 & \text { TF }\end{array}$ $\begin{array}{lllllllll}0.149 & 115 & 1.076 & 1.275 & 4.50 & 0.89 & 72823 & 2.85 & \text { TF } \\ 0.145 & 115 & 1.076 & 1.252 & 4.43 & 0.90 & 62200 & 2.85 & \text { TF }\end{array}$ $\begin{array}{lllllllll}0.145- & 115 & 1.076 & 1.252 & 4.43 & 0.90 & 62260 & 2.85 & \text { TF } \\ 0.149 & 115 & 1.084 & 1.301 & 4.61 & 0.90 & 56115 & 2.85 & \text { TF }\end{array}$ $\begin{array}{lllllllll}0.149 & 115 & 1.084 & 1.301 & 4.61 & 0.90 & 56115 & 2.85 & \text { TF } \\ 0.146 & 115 & 1.092 & 1.301 & 4.57 & 0.91 & 49185 & 285 & \text { TETF }\end{array}$ $\begin{array}{lllllllll}0.146 & -115 & 1.092 & 1.301 & 4.57 & 0.91 & 49185 & 2.85 & \text { TETF } \\ 0.142 & 115 & 1.085 & 1.269 & 4.50 & 0.92 & 42067 & 285 & \text { TETF }\end{array}$ $\begin{array}{lllllllll}0.149- & 115 & 1.094 & 1.264 & 4.76 & 0.91 & 40806 & 2.85 & \text { TETF }\end{array}$ $\begin{array}{llllllllll}0.149- & 115 & 1.092 & 1.252 & 4.81 & 0.90 & 37150 & 2.85 & \text { TETF }\end{array}$ $\begin{array}{llllllllll}0.148 & - & 126 & 1.093 & 1.272 & 4.84 & 0.9132645 & 285 & \text { LTPF }\end{array}$ $\begin{array}{llllllllll}0.144- & 126 & 1.098 & 1.267 & 4.76 & 0.92 & 29127 & 2.85 & \text { LTPF }\end{array}$ $\begin{array}{lllllllll}0.154 & -126 & 1.073 & 1.225 & 5.11 & 0.87 & 29591 & 2.85 & \text { LTPF }\end{array}$ $\begin{array}{lllllllll}0.155- & 126 & 1.069 & 1.243 & 5.20 & 0.87 & 27477 & 2.85 & \text { LTPF }\end{array}$ $\begin{array}{llllllllll}0.155 & 0.125 & 126 & 1.075 & 1.215 & 5.24 & 0.87 & 20952 & 2.85 & \text { LTPF }\end{array}$ $\begin{array}{llllllllll}0.156 & 0.085 & 91-126 & 1.070 & 1.183 & 5.33 & 0.86 & 13156 & 2.85 & \text { UTPF }\end{array}$

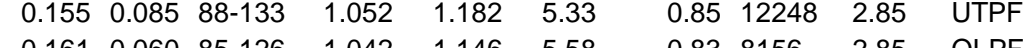

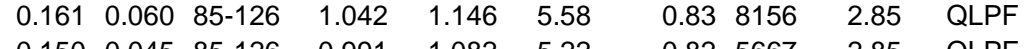

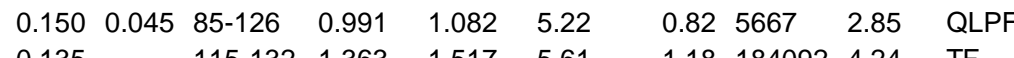
$\begin{array}{lllllllll}0.135- & 115-132 & 1.363 & 1.517 & 5.61 & 1.18 & 184092 & 4.24 & \text { TF } \\ 0.133 & 115-132 & 1.357 & 1.511 & 5.54 & 1.19 & 180172 & 424 & \text { TF }\end{array}$ $\begin{array}{lllllllllllllll}0.133 & 115-132 & 1.357 & 1.511 & 5.54 & 1.19 & 180972 & 4.24 & \text { TF } \\ 0.132 & 115-132 & 1.362 & 1.507 & 552 & 1.20 & 177550 & 424 & \text { TF }\end{array}$ $\begin{array}{llllllllll}0.132 & 115132 & 1.362 & 1.507 & 5.52 & 1.20 & 17750 & 4.24 & \text { TF } \\ 0.132 & 115-132 & 1.359 & 1.497 & 556 & 1.19 & 170308 & 4.24 & \text { TF }\end{array}$ $\begin{array}{lllllllll}0.132 & 115-132 & 1.362 & 1.512 & 5.63 & 120 & 153190 & 424 & \text { TF }\end{array}$ $\begin{array}{llllllllll}0.143 & - & 115-142 & 1.403 & 1.559 & 7.06 & 1.18 & 200683 & 5.03 & \text { TF }\end{array}$

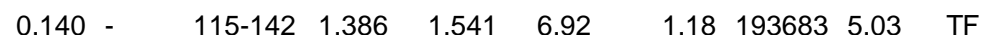

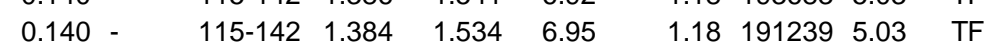

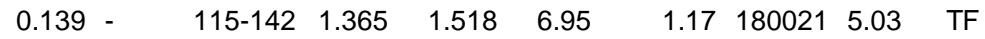
$\begin{array}{lllllllll}0.140 & -115-142 & 1.381 & 1.531 & 7.09 & 1.18 & 164050 & 5.03 & \text { TF }\end{array}$ $\begin{array}{lllllllll}0.143 & -115-142 & 1.384 & 1.564 & 7.35 & 1.17 & 142520 & 5.03 & \text { TF }\end{array}$

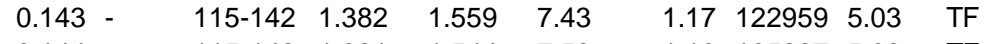
$\begin{array}{llllllllll}0.144- & 115-142 & 1.381 & 1.544 & 7.58 & 1.16 & 105227 & 5.03 & \text { TF }\end{array}$

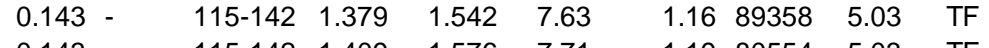

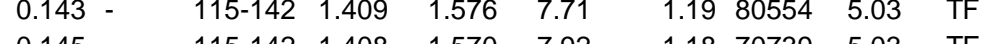
$\begin{array}{lllllllll}0.145- & 115-142 & 1.408 & 1.570 & 7.92 & 1.18 & 70739 & 5.03 & \text { TF } \\ 0.145 & 115-142 & 1.411 & 1.570 & 8.00 & 1.18 & 63209 & 5.03 & \text { TF }\end{array}$

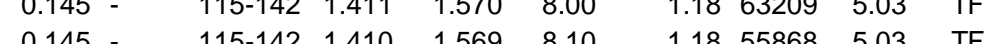
$\begin{array}{lllllllll}0.145- & 115-142 & 1.410 & 1.569 & 8.10 & 1.18 & 55868 & 5.03 & \text { TF } \\ 0.145- & 115-142 & 1.421 & 1.584 & 8.18 & 1.19 & 51468 & 5.03 & \text { TF } \\ 0.143- & 115-142 & 1.410 & 1.572 & 8.14 & 1.19 & 4599 & 5.03 & \end{array}$ $\begin{array}{llllllllll}0.143 & 115-142 & 1.410 & 1.572 & 8.14 & 1.19 & 45979 & 5.03 & \text { TF }\end{array}$ $\begin{array}{llllllllll}0.146 & - & 126-142 & 1.423 & 1.586 & 8.43 & 1.19 & 41897 & 5.03 & \text { TF }\end{array}$ $\begin{array}{lllllllll}0.143 & -126-142 & 1.428 & 1.577 & 8.35 & 1.21 & 37624 & 5.03 & \text { TF }\end{array}$

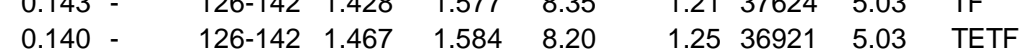
$\begin{array}{lllllllll}0.140 & -126-142 & 1.433 & 1.594 & 8.28 & 1.22 & 33210 & 5.03 & \text { TETF }\end{array}$ $\begin{array}{lllllllll}0.141 & 126-142 & 1.425 & 1.579 & 8.41 & 1.21 & 31332 & 5.03 & \text { TETF }\end{array}$ $\begin{array}{llllllllll}0.140 & 0.105 & 126-142 & 1.419 & 1.574 & 8.44 & 1.21 & 21421 & 5.03 & \text { LTPF }\end{array}$ $\begin{array}{llllllllll}0.141 & 0.065 & 126-142 & 1.404 & 1.527 & 8.56 & 1.19 & 12498 & 5.03 & \text { LTPF }\end{array}$

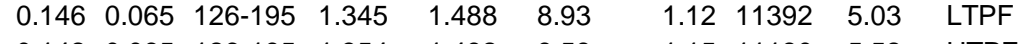
$\begin{array}{llllllllll}0.142 & 0.065 & 126-195 & 1.354 & 1.492 & 9.58 & 1.15 & 11180 & 5.52 & \text { UTPF } \\ 0.149 & 0.045 & 88-142 & 1.349 & 1.467 & 10.12 & 1.12 & 7386 & 5.5 & \text { UTPF }\end{array}$

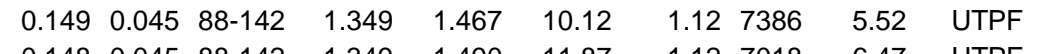

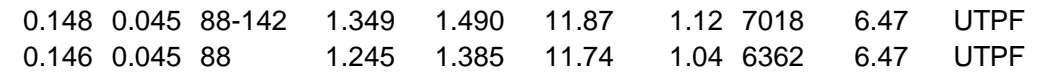

city ranges, sorted from $10 \mathrm{w}$ h high velocit (numbers before hyphen), and 27 ranges in clay concentration, sorted from low to high concentration (numbers after hyphen). This numbering system facilitates comparison of Th

region of plug flow $\tau_{0}=$ mean bed shear stress; $\mathrm{Fr}=$ Froude number; $\mathrm{Re}=$ Reynolds number; TF $=$ turbulent flow: TETF = turbulence enhanced transition

$\tau_{b}=$ mean
flow; LTPF = lower transitional plug flow; UTPF = upper transitional plug flow; QLPF = quasi-laminar plug flow; (d) = depositional flow 